\title{
Observaciones sobre la Hermandad castellana en tiempos de Enrique IV y los Reyes Católicos
}

\author{
José María Sánchez Benito *
}

\begin{abstract}
RESUMEN ABSTRACT
El objetivo de este artículo es el estudio de la formación y funcionamiento de la Hermandad

General castellana desde 1464 hasta 1476, esto es, entre los reinados de Enrique $\mathrm{IV}$ y los Reyes Católicos. A tal fin, se ha procedido al análisis de las diferentes etapas de su evolución, poniendo en evidencia el impulso que dio la Corona a la institución, primeramente en respuesta a la violenta oposición de la nobleza y, después, como un instrumento de gobierno en manos de la monarquía.

The objective in this article is to study about formation and functioning of the Hermandad General of Castilian since 1464 until 1476, that is, between Henry IV and Catholic Kings reigns. For that reason, we have analyzed the different periods of its evolution, demonstrating that the Crown impelled the institution, first in response to violent opposition that was suffering by the sovereign, and later, like and instrument of government at the hands of monarchy.
\end{abstract}

Hace ya unos cuantos años dediqué alguna atención al estudio de la Hermandad General que los Reyes Católicos impulsaron en Castilla hasta 1498. Como resultado de dichas pesquisas publiqué varios trabajos entre los años 1987 y 1993, insistiendo especialmente en la formación y despliegue de la institución, las dificultades que se opusieron a ello, así como

* Universidad Autónoma de Madrid. 
el papel centralizador que desempeñó en este reinado '. Sin embargo, quedó bastante al margen de aquella investigación la época inmediatamente precedente, es decir, los años difíciles de Enrique IV, cuando entonces, como es bien sabido, las ciudades vieron en su asociación una salida para dar respuesta a la inestabilidad política.

Así pues, en el presente artículo pretendo profundizar en el conocimiento de las hermandades constituidas en estos tiempos, poniendo en evidencia la relación muy importante que existe con respecto a la corporación que posteriormente desarrollaron los Reyes Católicos. Al servicio de estos objetivos he recurrido, como no podía ser de otro modo, a los ordenamientos - que ya son conocidos-, pero muy especialmente a la documentación local, muy poco utilizada hasta ahora para estos fines, pero que, como comprobaremos, permite iluminar no pocas cuestiones.

Es sabido que en el reinado de Enrique IV, la Hermandad emerge en Castilla, durante el mes de septiembre de 1464, en unas circunstancias políticas de gran inestabilidad. Seguramente no es oportuno profundizar una vez más esas circunstancias y repetir acontecimientos que son bien conocidos, pero, en todo caso, valga recordar que por entonces el enfrentamiento del soberano con la oposición nobiliaria alcanzaba tal virulencia que el marqués de Villena y el maestre de Calatrava, con abundantes tropas, llegaron a intentar nada menos que copar al rey en Villacastín ${ }^{2}$. Resulta fácil entender que aquello suponía, sin la menor duda, el enfrentamiento abierto, y sus consecuencias por fuerza tenían que contagiar a toda la sociedad castellana.

En estas condiciones, las pendencias que afectaban al rey y a los grandes encontraban una traducción inmediata en las ciudades. Inevitablemente, la vida urbana se veía profundamente alterada, en las calles pugnaban los bandos al compás del acontecer político del conjunto del

\footnotetext{
Los artículos referentes a estos asuntos son los siguientes: "La organización territorial de la Hermandad General (1476-1498)", Revista de Estudios de la Administración Local y Autonómica, 239, 1988, pp. 1509-28; «El proceso constituyente de la Hermandad General. Los ordenamientos de 1476 a 1478 ", AHDE, 1989, pp. 633-98 (en colaboración con Y. Guerrero NavarRETE); «Notas sobre la junta general de la Hermandad en tiempos de los Reyes Católicos", Anales de la Universidad de Alicante. Historia Medieval, 8, 1990-91; "La implantación de la Hermandad General en tierras de la nobleza: los estados del duque de Alba (1476-79)", En la España Medieval, 16, 1993, pp. 265-86 (en colaboración con D. C. MORALES MUÑIZ). También la pequeña recopilación titulada Castilla, los Reyes Católicos y la Hermandad General (1475-1498), Cuenca, 1990, cuya distribución fue mínima.

2 Un panorama de todos estos acontecimientos en L. SuÁREZ FERnANDEZ, “Los Trastámaras de Castilla y Aragón en el siglo XV», en Historia de España dirigida por R. Menéndez Pidal, Madrid, 1970, pp. 253-97.
} 
reino y, en definitiva, proliferaba el desorden y hasta la violencia. En el caso de Cuenca - que es la ciudad que va a servirnos como hilo conductor-podremos comprobar la incidencia de toda esta problemática, en cuyo marco la formación de una Hermandad general fue tomando cuerpo.

Avanzado el mes de septiembre, y por iniciativa del obispo Lope Barrientos - que era un firme defensor de la causa monárquica y por orden del rey tenía la guarda de la ciudad-, las divisiones existentes y el gran riesgo que suponían para la paz interna de la ciudad, obligaron a exigir públicamente juramento de fidelidad al soberano. Lo que el obispo quería era excluir a quienes estuviesen contra el rey y, por lo tanto, aquellos que no quisiesen prestar el juramento tenían que abandonar el recinto ciudadano. Al mismo tiempo, se estaban recibiendo en el concejo varias cartas reales narrando parte de los enfrentamientos que habian tenido lugar en el reino contra ciertos nobles -el marqués de Villena, el maestre de Calatrava, los condes de Alba y Treviño, el almirante y su hermano-, pidiendo lealtad al trono e indicando que cuantos fuesen contrarios a la Corona abandonasen el núcleo urbano. También se ordenaba con insistencia que, junto a Moya y Requena, los conquenses estuviesen dispuestos para defender la tierra a las órdenes del obispo Barrientos ${ }^{3}$. En fin, este es el contexto en el que, simultáneamente a todo lo anterior, llegaba un primer mandato regio para que los conquenses y todas las localidades importantes del entorno se agrupasen en hermandad para su mejor protección y para favorecer la justicia real ${ }^{4}$. A tal fin, se disponía que las localidades comarcanas enviasen procuradores a Cuenca para proceder a su organización en presencia del prelado. Es claro que al mismo correspondía una función directiva no sólo en lo referente a la iniciativa hermandina sino en todo el dispositivo político de la región y en él se apoyaba toda la acción monárquica en estas tierras. Naturalmente, y esto no puede sorprender a nadie a tenor de la posición que tenía el marqués de Villena frente al soberano, en ningún momento se sugiere la incorporación de las villas de su señorio.

Lo que resulta evidente, por tanto, es que la realeza, acosada y en graves dificultades, trataba de dar respuesta a la amenaza nobiliaria articulando unas medidas de defensa que asegurasen su predominio en grandes áreas del reino. Esa, y no otra, es la lógica a la que res-

A.M.Cu. leg. 196, exp. 2, fols. $109 r-113 v$ y $114 r-116 v$.

A.M.Cu. leg. 196, exp. 2, fols. $115 \mathrm{v}-116 \mathrm{r}$. 
ponde la naciente Hermandad, y por eso desde la Corte real se insiste mucho en su despliegue.

En este sentido, hay que tener muy en cuenta que lo que acabamos de ver en Cuenca no es en absoluto excepcional y que, por consiguiente, se despacharon mandatos similares para formar hermandades en las diferentes áreas regionales del reino, o al menos donde se podía encontrar una cierta aceptación para la causa regia. Podemos alegar una orden dirigida a Madrid muy pocos días más tarde para, junto con otras localidades, acudir a Segovia con el fin de organizar la institución. Como puede observarse, es lo mismo que antes hemos visto en el caso de Cuenca, sólo que en esta ocasión se señala fecha - ocho de octubre- para que los procuradores hiciesen acto de presencia en la ciudad segoviana ${ }^{5}$.

Claro que una cosa era dar órdenes para que se iniciase la andadura hermandina y otra muy distinta era la verdadera formación y consolidación de una empresa de estas características. Hay que pensar que las complicaciones no eran pocas y, por supuesto, la agrupación de distintos núcleos urbanos exigía la eficaz coordinación de los concejos, cuando el país vivía unas condiciones de notoria inseguridad y las comunicaciones no eran precisamente fáciles. Así las cosas, y volviendo al ejemplo conquense que nos sirve de hilo conductor, hay una nueva carta real, fechada a principios de noviembre de 1464, designando al corregidor y a Pedro Carrillo -que guarnecía la ciudad por orden del rey- para que, a petición del concejo, se encargasen de dar forma a la Hermandad que debía establecerse con las localidades de la región, de forma que se diesen las oportunas ordenanzas y se procediese al nombramiento de oficiales: alcaldes, alguaciles y cuadrilleros ${ }^{6}$. Lo que ocurre es que después, a lo largo del año siguiente, 1465 , los indicios existentes muestran que la institución no se consolidaba, mientras que proseguía la insistencia del rey a través de nuevas misivas y también los intentos para que el despliegue de la entidad se hiciese verdaderamente posible. Sin embargo, desde principios de febrero hasta fines de junio no hay nuevas noticias que muestren alguna actividad sobre este asunto y para esta última fecha sabemos que la unión realmente no se había verificado, no había alcaldes, ni se habían dispuesto las normas mínimas para que el engranaje previsto pudiera fun-

5 Documento publicado por T. Domingo, Documentos del Archivo General de la villa de Madrid, Madrid, 1888-1909, III, pp. 153-56. Hay una referencia relativa a la Hermandad de León en marzo de 1465, J. González Moreno, Serie documental española, Sevilla, 1977, n 350.

6 A.M.Cu. leg. 197, exp. 2, fols. $48 v-49 r$. 
cionar. Asi pues, la Corona tiene que volver a escribir para que se constituyese efectivamente la Hermandad y para ello se reuniesen procuradores. Además, hay otra cosa significativa, cual es que la documentación de estos momentos tan sólo habla, a este respecto, de la adhesión de Moya y Requena, alrededor del núcleo conquense, y no ya de otras poblaciones en las que -como es el caso de Huete ${ }^{7}$ - no se podía esperar una actitud favorable a las propuestas que viniesen del rey. Sólo entrado julio se empezará a contar también con Molina ${ }^{8}$.

Ahora bien, en el mes de septiembre sabemos que el concejo de Madrid procedía al nombramiento de dos alcaldes ${ }^{9}$, y si en estas fechas no contamos con información similar para Cuenca, este dato nos permite comprobar cómo la institucionalización hermandina estaba avanzando en algunos rincones de Castilla y, en particular, en el ámbito que a estos efectos se orientaba alrededor de Segovia.

Pero, en definitiva, lo que queda claro es que estamos en presencia de una iniciativa regia que hay que entender en el contexto de la virulenta contestación que sufría el soberano y en la lógica de la guerra. El rey lo que pretendía no era otra cosa sino tomar posiciones favorables, buscaba apoyos y también procuraba en lo posible levantar obstáculos frente a sus oponentes. En esto reside verdaderamente el origen de la Hermandad. Por lo demás, en cuanto se refiere a la organización de la misma, hemos visto que se avanzó poco, si bien, las ideas que sobre esto se manejaban y que la Corte quería hacer llegar a las ciudades partían siempre de un planteamiento regional, de forma que en cada sector territorial las villas y ciudades se aliasen alrededor de un núcleo urbano más importante, llamado a centralizar el esfuerzo. A partir de ahí, en la actividad defensiva que los hermanados debían desarrollar, se recurre como elemento clave al "apellido", como fórmula de movilización de la gente de cada lugar para perseguir a cualquier agresor. Al mismo tiempo, se quería también la instauración del binomio formado por alcaldes y cuadrilleros, ya consagrado desde mucho antes por la Santa Hermandad Vieja de Toledo, Talavera y Ciudad Real, y cuya fina-

\footnotetext{
Bajo la supremacía verdaderamente absorbente de Lope Vázquez de Acuña, el papel de Huete en el conflicto civil castellano no podia ser favorable al rey. Por eso, a fines de 1465 se hizo un intento para tomar su fortaleza en el que participaron cuarenta de a caballo y unos doscientos peones y ballesteros de Cuenca y su tierra. La empresa fracasó cuando apareció el arzobispo Alfonso Carrillo desbaratando a lo sitiadores. A.M.Cu. leg. 197, exp. 1, fol. 26r-v y leg. 197, exp. 5, fol. $4 r-v$.

8 A.M.Cu. leg. 197, exp. 2, fols. 43r-v, 44v-51r, 59v, 60v, y leg. 5, exp. 6.

9 A. Millares y J. Artiles, Libro de acuerdos del concejo madrileño, I. 1464-1485, Madrid, 1932 , ค. 8.
} 
lidad consistía en asegurar cotidianamente el orden público mediante un armazón estable que permitiese ejercer funciones jurisdiccionales -a través de los alcaldes- $y$, al mismo tiempo, tener presencia en el territorio - los cuadrilleros-.

A lo largo de 1466 la evolución de la Hermandad entra en una nueva etapa que bien podríamos denominar época de las juntas y que se distingue nítidamente con respecto al periodo precedente que acabamos de ver. Entonces, según hemos mostrado, la Hermandad había brotado de manos del rey en el convulso panorama político castellano, pero ahora las cosas van a desarrollarse de otra manera.

Cerca del verano de este año el estado que presentaba la institución se caracterizaba por la desigualdad, de manera que en algunos sitios se había constituido una cierta organización y en otros no. Pero lo más importante es que, en un contexto global de desorden y enfrentamiento civil, el concepto hermandad, a pesar de todo, llegaba ya a todas partes, y si no se había traducido en un sistema eficaz de instituciones, sí se fue introduciendo en las conciencias como una herramienta perfectamente válida en tiempos de inestabilidad. Una herramienta que de alguna manera contribuía a llenar el vacio de autoridad que el enfrentamiento civil había producido.

En agosto se celebró la junta general de Medina del Campo ${ }^{10}$, la primera que conocemos, y en ella la atención se concentró esencialmente en todo lo relativo a la inseguridad por entonces reinante y en las vías para su superación. A esto se dedicó la inmensa mayor parte del ordenamiento que allí se hizo, aunque, en realidad, dichas vías no suponían nada nuevo, pues se recurrió a unos mecanismos bien conocidos y que además ya habian salido a relucir desde el otoño de 1464 . Se trata en primer lugar del "apellido", para movilizar a la gente y perseguir a cualquier agresor de pueblo en pueblo, también los alcaldes y cuadrilleros, y en tercer término la ayuda mutua entre las poblaciones, particularmente entre las más próximas. Pero, en fin, lo que se deduce con mayor claridad de la lectura de lo acordado en Medina es que la Hermandad se estaba empezando a organizar. Por eso se insiste mucho en la integración en ella de las ciudades y no se prevé otro mecanismo conjunto que la junta general. Pero claro, la perspectiva no era ya regional, como

10 J. L. Bermejo Cabrero, "Hermandades y comunidades de Castilla", $A H D E, 1988$, ha publicado tanto este ordenamiento como los posteriores de las juntas de Fuensalida, segunda de Medina, Cantalapiedra y Madrigal, pp. 343-412. En el presente artículo se han utilizado los textos editados por este autor y todas las citas relativas a dichos ordenamientos se refieren a ellos. 
lo fuera al principio, sino global, pretendiendo la generalización de la entidad a todo el reino.

En esta misma junta quedó convocada la siguiente para el mes de noviembre en Santa Olalla, y efectivamente las reuniones se irán sucediendo a partir de entonces, y durante los años 1466 a 69 , a un ritmo variable pero bastante vivo, alguna vez con un único mes de intervalo y, en general, cada cuatro meses de media más o menos. De esta forma, la Hermandad se fue configurando al paso de las juntas generales, y éstas, como se sabe, constituirán la columna vertebral de la unión de ciudades.

Por lo que indican las propias actas de la junta de Medina, los núcleos que asistieron no fueron muchos - Madrid, Avila, Palencia, León, Benavente, Medina de Ríoseco, Zamora, Toro, Palenzuela y Salamanca, junto con varios distritos rurales en las inmediaciones de Toledo y Madrid- y, lógicamente, Cuenca no estuvo presente entre ellos. Sin embargo, los conquenses si fueron convocados mediante carta real ${ }^{11}$ a la siguiente que, según lo que hemos indicado más arriba, debía celebrarse en Santa Olalla al cabo de tres meses. La respuesta a la convocatoria no se hizo esperar y de manera inmediata los miembros del concejo otorgaron poder bastante a tres procuradores «para entrar e nos encorporar en el cuerpo de la dicha Santa Hermandad... (y) puedan yr e vayan al dicho ayuntamiento a la dicha villa de Santa Olalla a se juntar con los otros procuradores de todas las otras çibdades e villas e logares de los dichos regnos e señoríos e poner e encorporar la dicha çibdad de Cuenca e todos los lugares de su tierra en el dicho cuerpo de la dicha Santa Hermandad e asy encorporadas puedan tratar con ellos.... ${ }^{12}$.

Pero antes de que la asamblea hermandina tuviera lugar, llegó a Cuenca carta de la Mesta, reunidos en Berlanga, aludiendo a los males que el reino padecia y a su especial repercusión sobre los ganaderos trashumantes ${ }^{13}$. Los mesteños veían en la Hermandad una cierta solución que podría traerles la seguridad que tanto necesitaban para sus tráficos y por eso querían estar cerca de la institución - «con las quales

11 A.M.Cu. leg. 5, exp. 10. Podemos añadir otra carta real semejante, cuatro días posterior, dirigida a Madrid y publicada por T. Domingo, op. cit., Ili, pp. 177-79. No obstante, hay que hacer constar que estas cartas reales indican expresamente que la junta se convocaba por decisión de la anterior celebrada en Medina y, por tanto, no por iniciativa del rey.

12 A.M.Cu. leg. 197, exp. 5, fol. 80r-v.

13 A.M.Cu. leg. 197, exp. 5, fol. 77r. Es oportuno recordar con respecto a esto que en octubre del año precedente, 1465, y dada la inseguridad existente, la villa de Molina escribia al concejo conquense mostrando su temor porque al descender sus ganaderos hacia extremo podrian sufrir asaltos. A.M.Cu. leg. 197, exp. 1, fols. $7 \mathrm{r}-8 \mathrm{r}$. 
(hermandades) nosotros estamos determinados de nos juntar para dar alguna forma de remedio a los males" - y trabajaban para que efectivamente se consolidase. A esas razones respondia la carta dirigida a Cuenca, cuya finalidad, en suma, no consistía en otra cosa sino en que la ciudad ingresase sin tardanza en la corporación hermandina, y con la misma intención habían escrito también al obispo Barrientos, del que esperaban su apoyo a la causa y, más que eso, la capacidad de dirección que indiscutiblemente tenía. Posteriormente, según testimonio de 1468, sabemos que las cuadrillas mesteñas se entendían insertas en la gran asociación de ciudades ${ }^{14}$.

En noviembre, los hermanados se reunieron en Fuensalida -y no en Santa Olalla como se había previsto- sin duda con muchos más asistentes que en la junta anterior. En el curso de las sesiones, partiendo de lo hecho en Medina, se trataron cuestiones de jurisdicción y seguridad, aunque más bien aclarando los preceptos anteriores. Se acordó, asimismo, hacer repartimiento para poder contar con gente armada y se insistió en la entrada de las ciudades que no lo habían hecho, sin olvidar asuntos diversos pero de tanto calado político como era la preservación del realengo, el maestrazgo de Santiago, el rechazo al pago de pedidos y monedas, e igualmente se perfiló algo más el breve esquema burocrático de la propia Hermandad ${ }^{15}$. En este aspecto, hay que destacar - aunque explícitamente el ordenamiento de la junta no to trata- que ya existía una cierta organización provincial, alrededor de los centros urbanos más importantes.

De esta junta de Fuensalida se conoce un informe que se elaboró para Enrique IV y que resulta particularmente interesante para entender lo que fue aquella reunión y, más allá de esto, el ambiente en el que se estaba constituyendo la organización ${ }^{16}$. En dicho informe tan sólo se habla de aquellos temas tratados por los hermanados que tenían una mayor relevancia política desde el punto de vista del rey. Entre ellos, la

\footnotetext{
${ }^{14}$ Una carta de 14 de marzo de 1468, referente a los padrones para la financiación y movilización de las tropas de la Hermandad y remitida por los diputados generales de la misma a las ciudades y villas de la provincia conquense, incluye entre los destinatarios a la cuadrilla de la Mesta. A.M.Cu. leg. 198, exp. 2, fol. 16r-v.

${ }_{15}$ En concreto se regula algún aspecto de las juntas generales, que constituyen la clave de la institucionalización hermandina, y asimismo se crean seis escribanos de las juntas y un escribano de cada provincia.

16 Este informe ha sido publicado por J. L. Bermejo Cabrero, op. cit., pp. 341-43. Conocido desde hace ya mucho tiempo, T. DE AzCONA, Isabel la Católica, Madrid, 1986, I, p. 96 (la primera edición se publicó en 1964), lo fechó erróneamente en 1464 y posteriormente A. ÁLVAREZ DE MORALES, Las hermandades, expresión del movimiento comunitario en España, Valladolid, 1974, p. 126, aunque se dio cuenta y quiso acercarse más a la realidad, lo situó en 1467 y tampoco acertó.
} 
preservación del realengo, el maestrazgo de Santiago y los pedidos y monedas, pero también se destaca la enorme importancia que los representantes de las ciudades daban a la pacificación del reino y su disposición para entender en ello: "tyenen determinado de ver esta justiçia por las mejores vyas que pudieren, o deputar personas buenas e de conçiençia que entiendan en ello e lo fagan pospuesta toda afecto e parçialidad". Cierto es que el autor del informe no parece creer mucho en estos remedios y más se inclina por el acuerdo entre Enrique IV y su hermano, el príncipe Alfonso.

En un marco político determinado por la violencia y la crisis de la autoridad regia, los representantes ciudadanos comprenden perfectamente que no pueden evitar el influjo de las parcialidades que dividen el reino y que en cada lugar predominan en mayor o menor medida. Lo que les importa es la seguridad, el orden y, como no, la afirmación de los concejos y sus integrantes. Por esto último rechazan las intervenciones de la Corona en la vida local mediatizando la elección de procuradores a Cortes o nombrando nuevos oficiales locales. Del mismo modo, cuando los hermanados insisten, una y otra vez, en la preservación del realengo, lo hacen pensando en la influencia que sobre el mismo ejercían las corporaciones concejiles y las élites dominantes instaladas en el poder municipal ${ }^{17}$.

A partir de esta junta y, particularmente, una vez iniciado el año 1467, la Hermandad comienza a cristalizar en el ámbito conquense $y$, hay que entender -creo yo- que lo mismo ocurrió en casi todas las regiones de Castilla. Por una parte, la base de la nueva corporación se iba ensanchando con presteza, de forma que pronto ingresó Molina al lado de Cuenca y lo mismo hicieron muchos señoríos cercanos, cual Monteagudo, Priego y la Obispalía ${ }^{18}$, aunque alguno, como Monsalud, no lo hiciera hasta el año siguiente ${ }^{19}$. Por otra, se dio forma al esquema organizativo de la Hermandad, nombrando alcaldes y escribano ya en diciembre de $1466{ }^{20}$, del mismo

17 J. M. Minguez, partiendo del estudio de las hermandades más antiguas ha observado esto con acierto, señalando que hay un común interés entre la realeza y las oligarquias locales en torno al realengo, pero «mentras que para la monarquía el realengo comienza a ser contemplado bajo el prisma de la centralización, para los representantes cocejiles la déensa del realengo se plantea desde la perspectiva de sus intereses de clase". En "Las hermandades generales de los concejos en la Corona de Castilla (Objetivos, estructura interna y contradicciones en sus manifestaciones iniciales", Concejos y ciudades en la Edad Media hispánica. II Congreso de Estudios Medievales, Madrid, 1990, p. 567.

18 A.M.Cu. leg. 198, exp. 1, fols. $26 v-27 r, 37 v-38 r$ y $105 r-106 v$.

19 A.M.Cu. leg. 198, exp. 2, fol. 5r-v.

20 Alcaldes y escribano se nombraban por plazo de seis meses y por eso se renovaron en junio. A.M.Cu. leg. 198, exp. 1, fol. 9r-v. 
modo que representantes de Cuenca acudirán a las juntas generales sucesivas y también se procedió a recaudar dineros para el sostenimiento de la institución ${ }^{21}$.

Pero se vivían tiempos de verdadero desorden en los que no pocos poderosos aprovechaban para redondear sus estados e incluso para cometer toda clase de abusos. Además, cerca de la ciudad conquense nobles contrarios a Enrique IV tenían posiciones muy sólidas. Así pues, el desenvolvimiento de la Hermandad no iba a ser fácil —ni a nivel general ni a nivel local- y su función como mecanismo de ayuda mutua mostró inevitablemente sus limitaciones.

En estas condiciones, hubo conflicto abierto entre la villa de Requena y su señor, Alvaro de Mendoza, que actuaba desde el castillo local. El enfrentamiento se venia prolongando desde antes del invierno y debió adquirir gran dureza, incluyendo la quema de sembrados por parte del noble, mientras los de la villa dificultaban el acceso de viveres a la fortaleza y recurrían a la Hermandad con el apoyo del rey ${ }^{22}$. Se vio el caso en las juntas generales de noviembre de 1466 y abril de 1467, y por decisión de la última se quiso poner tregua entre los contendientes, pero al finalizar la primavera las cosas seguían en el mismo estado, muy lejos del acuerdo, reclamando una vez más los requenenses el apoyo de Cuenca ${ }^{23}$. Por los mismos días de junio de 1467, Moya reclamó ayuda semejante contra el mismo Alvaro de Mendoza, acusándole del robo de un millar de cabezas de ganado menudo, más los asnos y acémilas del hato ${ }^{24}$. Pero si desde Cuenca hubo alguna intervención, al menos mediadora, en el caso de Requena, y en ello se llevaban gastados más de 30.000 mrs. a mediados del invierno, a la petición de Moya se respondió negativamente, argumentando defectos de forma. Claro que en la villa afectada la negativa se entendía de otra manera: «bien nos tenemos por dicho que non avedes de acodir ... que acá se alaba Alvaro de Mondoça que segund la parte que en esa çibdad tiene bien sabe que non avedes de acodir» ${ }^{25}$. En Requena hubo

\footnotetext{
21 En febrero de 1467 los pueblos del sexmo conquense de la Sierra reclamaban a la ciudad que los dineros recaudados para la Hermandad se guardasen en ellos, porque por ser la distancia grande no era fácil ir a ella para tomar los caudales cuando hacian falta. Por cierto, no se conoce respuesta. A.M.Cu. leg. 198, exp. 1, fol. 4r-v.

22 En el mes de marzo los requenenses pedian ayuda al concejo de Cuenca, recordando una carta del rey que les instaba en el mismo sentido. A.M.Cu. leg. 198, exp. 1, fols. 12r y $24 r$.

23 A.M.Cu. leg. 198, exp. 1, fols. $5 r-v$ y $12 r-19 v$.

24 A.M.Cu. leg. 198, exp. 1, fol. 10r.

25 Hay noticias posteriores, de 1469, que son significativas a este respecto. En agosto de este año el corregidor de Cuenca, Pedro Barrientos, se comprometía a ayudar a Alvaro de Mendoza, especialmente en la guarda y posesión de la fortaleza de Requena, A.H.N. Diversos,
} 
guarnición respaldada por el rey y llegado el verano parece que éste animó un cierto acuerdo con el noble, pero todavía a fines del año se instaba al concejo conquense para que ayudase a la villa con armas y pertrechos ${ }^{26}$.

Naturalmente, se requirió la acción hermandina en otras ocasiones y en ningún caso parece que la eficacia fuese mucho mayor. Sin duda, en tiempos de tanta inestabilidad todos tenían razones para sentirse inseguros y trataban de buscar en la Hermandad el punto de apoyo que de otra manera no podian encontrar. Por eso siempre se pide la colaboración de las localidades comarcanas y del núcleo principal, que en esta región era Cuenca, además de llevar todos los asuntos de cierta importancia a las juntas generales. Pero lo que se observa es que la ayuda que verdaderamente cabía encontrar en las demás poblaciones era muy limitada - por no decir nula-y, además, dependía de los condicionamientos políticos de cada zona y de las posibilidades materiales, siempre escasas y en gran medida dedicadas a las amenazas que repercutían directamente sobre cada lugar. Así las cosas, la ciudad de Huete, por completo sometida a Lope Vázquez de Acuña - que a la superioridad que ejercía desde el castillo local, unía fuertes posiciones en la tierra y no dudaba a la hora de realizar toda clase de abusos- se quejó de enfrentamientos y daños. Igualmente, la villa de Molina escribió reclamando justicia por razón de los robos de Martín de Salinas y tan sólo encontró pegas de carácter formal y, finalmente, cuando los de Pareja informaron del mal trato que los cuadrilleros de la Hermandad habian encontrado cuando fueron a prender a un cierto vaquero de Alcocer, en Cuenca se decidió escribir al alcaide que parecía haber causado tales molestias ${ }^{27}$.

En suma, aunque sus limitaciones fuesen notorias para todos, la Hermandad se desplegaba y empezaba a funcionar. Como sabemos, las juntas generales constituían el verdadero núcleo de la institución y en ellas no sólo se dictaban nuevas normas sino que también se estudiaban y determinaban toda clase de asuntos y conflictos. En abril se reunió por segunda vez en Medina del Campo y en sus ordenanzas ya no se atiende tanto a los problemas de jurisdicción y seguridad. La atención se dirige ahora hacia la vida económica del reino: moneda, acaparamiento de mer-

\footnotetext{
Colección Diplomática, leg. 47. En octubre era el concejo el que ordenaba al lugar de Campillo que llevase al noble cuatrocientas fanegas de trigo por su actitud favorable hacia la ciudad, A.M.Cu. leg. 198, exp. 3, fol. 110v

26 A.M.Cu. leg. 198, exp. 1, fols. $26 r-28 v$ y $103 r-105 v$

27 A.M.Cu. leg. 198, exp. 1, fols. $19 \mathrm{r}$ (con respecto a Huete), $11 \mathrm{r}-\mathrm{v}$ y $17 \mathrm{v}-18 \mathrm{r}$ (con respecto a Molina) y $10 \mathrm{v}-11 \mathrm{r}$ (el caso presentado por Pareja).
} 
cancías, exportación de cosas vedadas, portazgos, y por supuesto, se atiende más que nunca a la institucionalización de la entidad.

Inevitablemente, las decisiones de naturaleza económica adoptadas por la junta, cuyo trasfondo no es sino un deseo ideal de orden, por fuerza tenían que afectar intereses, cual, por ejemplo, los de la cuadrilla mesteña de Cuenca. Por tanto, los trashumantes no tardaron mucho tiempo en protestar al concejo de la ciudad por razón de la ordenanza que se había acordado por los reunidos en Medina del Campo para que no se pudiesen exportar ganados y cueros ${ }^{28}$. Claro que, por otra parte, estas normas de carácter mercantil no se podían cumplir fácilmente, de modo que en la asamblea de febrero de 1468 se volvió a insistir sobre ello y mucho más tarde, en octubre del mismo año, llegaba carta a Cuenca urgiendo la veda de la exportación de caballos. La respuesta del concejo a esta misiva hermandina resulta interesante para ver los obstáculos que se oponían a las normas de la corporación, pues lo que dicen los regidores conquenses es que las condiciones del arrendamiento de los diezmos y aduanas establecidas por la Corte real permitían dicha exportación ${ }^{29}$.

Pero dejando a un lado estos detalles y volviendo a la construcción de la Hermandad a lo largo de las sucesivas juntas generales que se iban celebrando, la verdad es que, en lo esencial, a partir de la segunda reunión de Medina el dispositivo de la entidad estaba completo. Por consiguiente, las ordenanzas de la siguiente junta, celebrada en Castronuño seis meses más tarde, son mucho más breves y tienen un carácter puramente complementario ${ }^{30}$, 10 mismo que las dos siguientes convocatorias, cuya celebración tuvo lugar en un plazo de tiempo muy breve, primero en Cantalapiedra, a fines de noviembre, y luego en Madrigal, durante el mes de febrero del siguiente año, 1468. No obstante, la fragmentación del país era grande y no resultaba nada fácil mantener la unidad de la Hermandad. Por eso seguramente se aceleró tanto el ritmo de celebración de las asambleas en estos meses.

En lo que se refiere a la organización, hay que señalar que por estas fechas había cristalizado ya suficientemente. El territorio castellano se dividía en provincias — una de las cuales, encabezada por Cuenca, com-

28 A.M.Cu. leg. 198, exp. 1, fols. 7v-8r.

29 A.M.Cu. leg. 198, exp. 2, fol. 53r-v. He estudiado, en general, las políticas referentes a la exportación en mi libro La Corona de Castilla y el comercio exterior, Madrid, 1993, y en lo que se refiere al ámbito conquense, en un articulo anterior: "Algunos aspectos del comercio bajomedieval en Cuenca: la intervención de la monarquía sobre los tráficos", Cuenca, 34, 1989, pp. 13-22.

30 El texto de este ordenamiento se conoce desde hace muchos años, fue publicado por $\mathrm{J}$. Puyol y Alonso, Las hermandades de Castilla y León, Madrid, 1913, pp. 105-25. 
prendía también Sigüenza y Molina ${ }^{31}$ - los oficiales de la Hermandad se designaban y funcionaban regularmente, y desde las juntas de Cantalapiedra y Madrigal tan solamente hubo un procurador de la demarcación conquense en cada una de las asambleas generales y no dos o tres como hasta entonces.

En el invierno de 1468, cuando la situación del país era de verdadero fraccionamiento, los diputados generales de la Hermandad comenzaron a negociar con diferentes nobles. Conocemos mal estos hechos, pero es posible constatar que tuvieron lugar varios encuentros sucesivos que culminaron en los capítulos establecidos a principios de la primavera en Tordesillas. Claro que antes de proceder a su análisis conviene tener en cuenta que en estos momentos había claros síntomas en el panorama político que empezaban a favorecer la causa del rey ${ }^{32} y$, desde luego, cabe preguntarse si la existencia de la Hermandad y su capacidad, tanto de presión como de negociación, no favorecieron decisivamente la aparición de dichos síntomas.

En cuanto a los capítulos de Tordesillas que ahora nos corresponde estudiar, lo primero que hay que mostrar es que se establecieron con los hijosdalgo y miembros de las órdenes militares "que han de tener y asentar las lanças con la corona real». En el texto, sin la menor duda, se viene a reconocer sus privilegios, empezando por el derecho a cobrar aquellos mrs. que cada uno de ellos tuviese en merced, y se afirma "que de aquí adelante los dichos regnos sean regidos por los tres estados ... vnidos e conformados", jurándolo así los reyes. Claro es que, al mismo tiempo, los caballeros ponían de manifiesto su lealtad al rey y reconocían expresamente el «santo propósito" de la Hermandad, así como sus ordenanzas y contribuciones fiscales ${ }^{33}$.

${ }^{31}$ Es significativo que una carta de los diputados generales de la Hermandad sobre los padrones elaborados para las necesidades militares de la misma se dirigió a las ciudades de Cuenca y Sigüenza, y a las villas de Molina, Pareja, Monteagudo, Huerta, Paracuellos, Escamilla, Requena y sus tierras, dejando a un lado casi todos los señoríos laicos de la zona. A.M. Cu. Leg. 198, exp. 2 , fol. $16 \mathrm{r}-\mathrm{v}$.

${ }_{32}$ Tenia razón L. SuÁREz Fernández cuando en su libro Nobleza y monarquía. Puntos de vista sobre la historia politica castellana del siglo xv, Valladolid, 1975, p. 221, escribia: “cuando un partido no conseguia imponer la victoria de un modo completo, la autoridad del monarca legítimo, por torpe y débil que fuese su titular, salía a flote en el mar encrespado de las pasiones políticas. Los pueblos encontraban siempre, en el fondo, el resorte de su adhesión al rey». Sobre la descripción de esta coyuntura política ver la obra del mismo autor, "Los Trastámaras...", cit., pp. 281-82.

${ }_{33}$ Capítulos otorgados a cinco de abril de 1468, A.M.Cu. leg. 19, exp. 1. En el texto se considera lo acordado como una más de las ordenanzas de la Hermandad, que así debia afirmarse en la próxima junta general que habia de celebrarse en el mes de junio en Valladolid. Así pues, no hubo junta en Tordesillas con motivo de este acuerdo. 
La siguiente etapa en la negociación entre hermanados y nobles tiene lugar en el mes de julio, después de la muerte del príncipe Alfonso, y consiste en el pacto al que llegan en Burgos los diputados generales de la asociación de ciudades y tres miembros muy destacados de la nobleza, claramente alineados con Enrique IV. Son éstos el conde de Haro, Pedro Fernández de Velasco, y su hijo Pedro; Diego Hurtado de Mendoza, marqués de Santillana, y el conde de Plasencia, Alvaro de Stúñiga, recientemente reconciliado con el soberano en un acercamiento que era buena muestra del refuerzo que en los últimos meses estaba teniendo la posición del monarca. Los tres grandes se comprometían a guardar la Hermandad y su «santo propósito», sus tierras ingresarían en la misma y ellos aceptaban poner a disposición de la corporación hasta trescientas lanzas cada uno. Llegaron a hablar de reunirse con los hermanados y los caballeros ya conformes con ellos para ver la manera de gobernar y pacificar el reino. Por su parte, los diputados generales garantizaban a los nobles el apoyo de la institución que representaban, incluso si personas de estirpe regia pretendían rebajar sus estados ${ }^{34}$.

Sin embargo, había un problema que venía latiendo desde la primera junta de Medina, del verano de 1466, y que habría de resultar decisivo para el futuro de la institución hermandina. Me refiero a la recaudación de dineros para contar con la gente armada que era necesaria para sostener el orden que la corporación preconizaba. Si ya desde aquella primera junta se preveía la posibilidad de organizar repartimientos, hay que esperar a la siguiente, celebrada en Fuensalida y de asistencia mucho más cuantiosa, para encontrar orden expresa disponiendo su puesta en marcha y dando plazo de treinta días para que cada concejo hiciera padrón. Después, las dos asambleas siguientes - Medina y Castronuño- lo que hacen es remitirse a lo acordado en Fuensalida, completando varios detalles, lo mismo que en la de Cantalapiedra, donde además se ordenó la presencia en la siguiente junta de la mitad de la gente de armas pagados por cuatro meses. A poco de iniciado el año 1468 el diputado de la Hermandad en la provincia de Cuenca notificaba la convocatoria de nueva junta general en febrero y la necesidad de llevar a ella la mitad de la fuerza de a caballo, tal como estaba establecido. El primer día de febrero la villa de Moya escri-

\footnotetext{
34 A.H.N.-Nobleza Osuna, caj. 1868-41. T. Azcona, op. cit., p. 116, dio cuenta de este acuerdo, aludiendo a las lanzas que los grandes estaban dispuestos a proporcionar. Ahora bien, no es inoportuno aclarar que con motivo de este entendimiento entre los nobles citados y la Hermandad no se celebró junta general de la misma. El pacto se estableció el 27 de julio en Burgos por parte de los nobles y el día 29 en el monasterio de Las Huelgas en lo referente a los diputados generales que mantenian la continuidad hermandina entre las juntas.
} 
bía, dispuesta a cumplir lo ordenado, preguntando la identidad del capitán a cuyas órdenes debían ponerse sus gentes para enviarlas cuanto antes ${ }^{35}$, y en el concejo conquense se nombró para tal cargo a Diego de la Vega, a la sazón, diputado provincial de la Hermandad ${ }^{36}$.

Es indudable la dificultad que entrañaba la movilización y financiación de esta tropa, por eso, aunque en el ámbito conquense se estaba llevando a cabo el esfuerzo que era necesario para poder contar con los efectivos armados, parece que no se mandó al lugar de la junta toda la fuerza prevista. Otras provincias debieron hacer lo mismo y asi se entiende la decisión que pocos días más tarde se adoptó en la junta general para reclamar los padrones de cada lugar, con la intención de comprobar si la gente armada que se había presentado era la debida. Además, se volvió a insistir en la necesidad de nuevos repartimientos.

Después, sabemos que hubo preocupación en el concejo conquense por estas mismas razones ${ }^{37} \mathrm{y}$, desde luego, todo parece indicar que se hicieron repartimientos ${ }^{38}$, pero también fue creciendo la resistencia a unas cargas que venían a sumarse a otras muchas.

Esta tendencia cristaliza en 1469, cuando entre el concejo y la Hermandad se abre una crisis, cuyas dos claves nos son ya conocidas: por una parte, los gastos que estamos señalando, y por otra, las limitaciones que inevitablemente tenía la institución y que imposibilitaban que los deseos de ayuda mutua se reflejasen en un apoyo concreto y real frente a las amenazas que aquejaban a las ciudades. A comienzos de febrero, en la junta reunida en Valladolid, se requirieron más dineros y el representante conquense, sabiendo la actitud que predominaba en su ciudad, "tomó término e deliberaçión para fablar con vosotros (el concejo) e consultarlo". Hubo, sin duda, presiones muy fuertes, pero en Cuenca el ambiente no era propicio para nuevos pagos y para evitarlos el concejo podía argumentar fácilmente la poca ayuda que en la práctica recibian a través de las instituciones hermandinas: "allende deso en repartimientos pasados e gastos desta Santa Hermandad avemos gastado más de trescientosmill mrs. e nuestro Señor sabe el poco fruto e prouecho que dello se nos ha seguido ... asy que pues en ningund aliuio ni remedio ni prouecho

\footnotetext{
A.M.Cu. leg. 198, exp. 2, fols. $6 r-v$ y $10 r-v$.

A.M.Cu. leg. 198, exp. 2, fol. 19r-v.

A.M.Cu. leg. 198, exp. 2, fol. 24r. En el mes de abril el concejo requería a los alcaldes de la Hermandad sobre la gente armada que habia que poner a disposición de la institución.

${ }_{38}$ En octubre y noviembre de 1468 el concejo dictó órdenes para tomar cuentas de los mrs. que se habían tomado para la Hermandad. A.M.Cu. leg. 198, exp. 2, fols. 32v y 58r.
} 
non avemos sentido, antes gasto e trabajo, non sabemos que mengua nos faga non gosar de los benefiçios de la Hermandad " ${ }^{39}$. Es verdad que mientras tanto la institución seguía funcionando en Cuenca y se seguían nombrando alcaldes ${ }^{40}$, pero los pocos contactos que se mantenían con los organismos centrales de la misma tenían un fuerte tono polémico y de verdadera ruptura - "entendemos que mucho más perderiades vosotros en non gosar de la libertad de la Santa Hermandad e sus leyes, que ella en perder a vosotros", llegan a decir los diputados generales ${ }^{41}$ - Finalmente, un representante conquense acudió a la junta de Medina de mayo de aquel año, por supuesto sin haber hecho nuevos repartimientos $y$, además, con una actitud dura de recriminación y crítica. Mientras tanto, en la ciudad ya no se contaba con la Hermandad, y si desde el concejo se ordenaba a los alcaldes de la entidad que concentrasen gente armada de la tierra en el núcleo urbano como medida de seguridad, también se disponía tomar cuenta de los dineros que hubiera en el arca hermandina para dedicarlos después a lo que fuese conveniente a la ciudad ${ }^{42}$.

Claro es que antes de todo esto, habían ocurrido cosas de gran trascendencia para el desarrollo de la entidad castellana. Me refiero particularmente al desfalco hecho por el tesorero de la Hermandad, Rodrigo del Río, y otros receptores de dineros de la corporación ${ }^{43}$. Es evidente que si en las ciudades de Castilla cundía el cansancio por las cargas económicas que suponía el sostenimiento de una organización como la que nos ocupa, un acontecimiento de esta clase venía a ser el colofón. Así las cosas, y teniendo en cuenta todos los factores que hemos venido planteando, no puede extrañar lo acordado en las Cortes de Ocaña, donde tras aludir a las muchas sisas, derramas y repartimientos, al pequeño fruto de tantos dineros y a las sospechas que sobre ello podía haber - «no podemos saber commo y en que cosa se gastaron tan grandes contías"-, se decidió diputar dos personas para que tomasen cuenta al tesorero de la institución ${ }^{44}$. Cierto es que lo ocurrido en las Cortes no se entiende bien sin tener en cuenta que, muerto el príncipe Alfonso, la situación política había cambiado mucho. Sin duda, la soberanía del rey era más difícil de discutir $y$, además, desde principios de año el marqués de Villena avanzaba en la reconciliación con los Mendoza ${ }^{45}$.

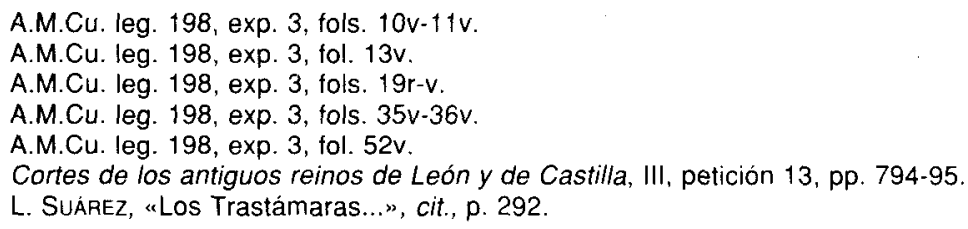


Como es lógico, la junta de Medina, que como sabemos tuvo lugar en el mes de mayo, debió ser muy difícil y cuando desde ella se dio respuesta a las airadas quejas de los conquenses lo que se observa es una actitud de inferior dureza. Los hermanados no podian hacer otra cosa sino ponderar la unidad de los pueblos, razonando que si contando con la institución no se habían obtenido los mejores remedios, peor estarían todos sin ella. Bien es verdad que seguían insistiendo en la necesidad de cobrar nuevos dineros - que quedarían en Cuenca para los gastos que alli se hicieran- y, desde luego, confirmaron la Hermandad y convocaron junta general para el primero de octubre en Madrigal.

En realidad, no sabemos si esta asamblea llegó a reunirse, pero lo que resulta indudable es que se atravesaba una situación de verdadera dificultad y había síntomas que ponían de manifiesto que las cosas habían cambiado con respecto a los tiempos anteriores. Entre esos síntomas hay que incluir lo que parece una mayor descentralización económica y, como no podía ser de otra manera en esta conyuntura política, hay una referencia a la corona muy explícita, pues, por ejemplo, se viene a indicar que las tareas de los diputados generales consistían básicamente en la justicia y, además, en la presentación al rey de las leyes de la Hermandad para que las mandase guardar o modificar ${ }^{46}$. Pero lo que hay que destacar muy especialmente es que a partir de ahora deja de haber noticias. Parece cierto que en el marco tan difícil que hemos expuesto, la Hermandad va perdiendo participantes y se vacía de contenido. Como hemos dicho antes, no se sabe si la siguiente junta, prevista para octubre, se llegó a celebrar.

Siguiendo el testimonio de Enriquez del Castillo se ha repetido que entonces las ciudades constituyeron pequeñas hermandades ${ }^{47} \mathrm{y}$, desde luego, no faltan ejemplos de ello ${ }^{48}$, pero es imprescindible aclarar que estas hermandades de ámbito local no eran nada nuevo y que durante

46 Las conclusiones que hemos extraído de la junta de Medina de mayo de 1469 se deducen de dos cartas, de 19 y 22 del mismo mes, remitidas por la Hermandad a Cuenca desde la misma junta. A.M.Cu. leg. 198, exp. 3, fol. 52r-v. J. L. Bermejo Cabrero, op. cit., p. 329, percibió que desde la muerte del príncipe Alfonso desaparece la ambigüedad de la Hermandad con respecto a la figura del rey.

47 L. SUAREZ, «Evolución histórica de las hermandades castellanas», CHE, 1951, p. 44.

48 En 1472 la ciudad de Avila escribía al conde de Alba, como a otras localidades comarcanas, notificándole su intención de formar una hermandad «para fazer seguro a todas las personas que fueren o vinieren e andovieren por los términos e caminos desta çibdad e su tierra, porque los delinquentes e malfechores de lo semejante sean punidos e castigados e non ayan logar de se acoger a otras tierras e jurediçiones" e instándole a adherirse con sus villas. Publica el documento J. M. CALDERón, Documentación medieval abulense en el Archivo de la Casa de Alba, Avila, 2000, n 59. 
los años inmediatamente anteriores hubo en Castilla numerosos ejemplos. No hay más que ver las ordenanzas de la junta de Fuensalida, que en uno de sus puntos mencionan una hermandad "en los honse sesmos de Segovia e en Madrid e su tierra e en la Sagra de Toledo e Casarruvios e el condado de Mançanares" ya existente desde tiempo antes, o la hermandad llamada del «Albogondiga Guadarrama aquende» con las villas de Maqueda, Santa Olalla, Torre de Esteban Ambrán y Puebla de Montalbán, que sabemos estaba en funcionamiento en $1467^{49}$.

En el caso de Cuenca consta el recibimiento de una carta de Albarracín en 1471 , notificando la propuesta de la ciudad aragonesa para formar hermandad por causa de los males que se estaban produciendo en la frontera. Desde luego, la reacción no fue en absoluto negativa y se señaló la conveniencia de juntar representantes de los núcleos urbanos fronterizos, incluyendo Moya y Molina, más los señoríos de la zona. Pero el concejo conquense mostraba también su intención de informar al rey, porque nada podría hacerse sin su consentimiento ${ }^{50}$. En todo caso, lo que queda claro es que, como en otros casos, mediante la formación de alianzas locales se quería dar respuesta al problema irresoluble de la inseguridad.

Así pues, este asunto, la inseguridad, será la clave sobre la cual se vuelve a organizar la Hermandad General castellana en 1473. Sólo que ahora la iniciativa vuelve a manos del rey, tal como ya ocurriera en 1464 , aunque en unas coordenadas políticas muy distintas a las de entonces y mucho más favorables para el prestigio y la superioridad de la monarquía. Por eso, la institución hermandina, que ahora renacía, será muy diferente a la existente entre 1466 y 1469 . En realidad, recogiendo el ansia de seguridad y orden que había en todo el reino, lo que se planteaba no era otra cosa sino un instrumento en manos del soberano, con capacidad para desplegar por todas partes una red de alcaldes y cuadrilleros que pudieran movilizar tropa suficiente para la persecución de malhechores y la consecución de unas mínimas condiciones de orden público. Esto, y no otra cosa, es lo que se puede encontrar al leer el ordenamiento de Villacastín de julio de 1473 , en el cual, para empezar, el rey es presentado como «cabeza et señor ... corazón et alma del pueblo» ${ }^{51}$. Volveremos sobre estas ordenanzas un poco más adelante, pero de momento quede claro que esta iniciativa regia poco tenía que ver con lo que la Hermandad había sido - o querido ser-

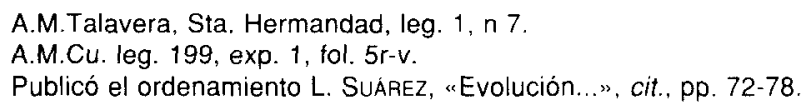


en los años inmediatamente anteriores, cuando el reino estaba radicalmente dividido entre las dos opciones que representaban el propio rey Enrique y su hermano Alfonso.

Todo indica que la organización recién creada contó con el apoyo del alto clero ${ }^{52} \mathrm{y}$, desde luego, sus dispositivos entraron en funcionamiento ${ }^{53}$, pero las noticias son muy reducidas y es poco lo que se puede decir con certeza sobre su actividad. En todo caso, aunque su desarrollo fuese limitado y su duración escasa, lo cierto es que supone un eslabón decisivo de cara a la posterior experiencia hermandina que muy pronto se iba a ensayar tras el ascenso al poder de los Reyes Católicos ${ }^{54}$.

En tiempos de los Reyes Católicos, aunque el inicio de la Hermandad suele situarse en las Cortes de Madrigal de 1476, el proceso que lleva a su nacimiento se había iniciado, sin duda, mucho antes ${ }^{55}$. Parece que en la Corte hubo conversaciones sobre la constitución de una entidad de esta clase desde el mismo ascenso al trono de la reina Isabel en $1474{ }^{56}$, y seguramente como consecuencia de estos tanteos - realizados sobre el recuerdo de la Hermandad recientemente formada a fines del reinado de Enrique IV - se produjo una temprana decisión regia, al poco de comenzar el año siguiente, consistente en la promulgación de un ordenamiento para que las ciudades y pueblos, tanto de realengo como de señorío, se uniesen en Hermandad ${ }^{57}$.

\footnotetext{
52 C. Olivera Serrano en su libro Las Cortes de Castilla y León y la crisis del Reino (1454-1474). El registro de Cortes, Burgos, 1986, p. 161, señalaba la participación de los eclesiásticos en esta nueva empresa hermandina. En este sentido, puedo señalar que a poco de promulgado el ordenamiento de julio de 1473, concretamente el tres de agosto, los miembros del Cabildo de la Catedral de Toledo aprobaron su ingreso en la Hermandad. A.C.To Actas Capitulares, 1309-1490, fol. 57.

53 A.M.Cu. leg. 5, exp. 13.

54 A. Alvarez de Morales, op. cit., p. 141, aludiendo a las ordenanzas de esta Hermandad, señala, utilizando la misma expresión que acabamos de emplear, que son eslabón decisivo.

55 En las páginas que siguen a continuación se han utilizado ideas ya perfiladas en las publicaciones que se citan en la nota 1 y particularmente en la recopilación Castilla, los Reyes Católicos..., cit., cuya difusión, como ya se ha indicado, fue mínima.

56 Asi lo indica, siguiendo a Alonso de Palencia, M. LunENFELD, The council of the Santa Hermandad, Miami, 1970 , p. 29, que interpreta la noticia cronistica diciendo lo siguiente: "Ferdinand gave some thoughts in 1474 to creating a league for his wife's cities".

57 Ordenamiento de 20 de febrero de 1475, Segovia, A.M.Cu. leg. 16, exp. 4 (original) y leg. 1145, exp. 2 (copia). No podrá pues hablarse de unas ordenanzas de Burgos de 1475 como afirmó J. Puyol, op. cit., p. 101. Por otra parte, L. Serrano, Los Reyes Católicos y la ciudad de Burgos, Madrid, 1943, p. 168, se refiere a un anuncio real en este sentido de 24 de enero del mismo año, 1475, estando los monarcas en Segovia. No dejaré de subrayar la referencia a esta localidad, desde la cual, como hemos indicado, se promulgó el ordenamiento de febrero del citado año.
} 
Así pues, no puede caber duda acerca de que estamos ante una decisión de la Corona que desde los primeros momentos ve en la Hermandad un recurso de utilidad - al menos temporalmente- para su tarea de gobierno. Todo esto se comprueba fácilmente en el texto de las ordenanzas que los soberanos promulgaron en febrero de 1475 , pues en ningún momento se hace referencia a petición alguna por parte de ninguno de los sectores de la sociedad y, antes al contrario, de lo que se trata, con toda claridad es de expresar la voluntad regia: «Bien sabedes e a todos es notorio quantas muertes e feridas de omes, e prisiones dellos, e robos, e tomas de bienes, e salteamientos, e otros delitos e maleficios son fechos e cometidos de dies años a esta parte ... e porque se presumen que algunos destos, continuando su mal veuir, tentarán de aqui delante de cometer o faser los tales e semejantes delitos, a lo qual nos, deseando faser e conplir con aquello a que somos obligados, entendemos, con la ayuda de nuestro Señor, obuiar, dando orden en la execuçion de la nuestra justicia como los tales maleficios çesen y los perpetradores dellos sean punidos, e los buenos biuan en pas e sosiego e a cada uno sea guardada su justicia, y para entre tanto que en esto damos orden y la ponemos en execuçion es nuestra merçed e voluntad que sean fechas hermandades por vosotros...". Así que no se puede deducir propuesta alguna por parte de las ciudades ni por ningún otro segmento social del reino. Simplemente, los soberanos trataban de reeditar una institución que había estado muy presente en los últimos años de la vida del país y en la que veían un instrumento que de forma temporal podría ser de utilidad en su política ${ }^{58}$.

Sin embargo, como es sabido, los meses subsiguientes resultaron particularmente difíciles para los nuevos monarcas, las circunstancias de la guerra civil les plantearon urgentes necesidades y la idea no pudo prosperar, interrumpiéndose desde el principio el desarrollo práctico de lo legislado en Segovia. De esta forma, la Hermandad prevista en las ordenanzas de 1475 nunca entró verdaderamente en vigor, pero tampoco quedó relegada al olvido y se conservó como un recurso político perfectamente válido para el porvenir. Naturalmente, resulta fácil comparar esto con lo ocurrido entre 1464 y 65 , cuando la iniciativa hermandina promovida por Enrique IV en momentos particularmente inestables no pudo consolidarse.

\footnotetext{
58 Paralelamente, se pensó cobrar los treinta millones de mrs., otorgados por las Cortes a Enrique IV, con el fin de allegar unos recursos económicos que por tantas razones eran imprescindibles en aquella coyuntura. L. Serrano, op. cit., p. 169; L. SuÁrez Fernández, "La España de los Reyes Católicos", en Historia de España dirigida por R. MENENDEZ PIDAL, Madrid, 1978, XVII, 1, p. 239.
} 
Posteriormente, mientras la apremiante situación del reino se clarificaba, la idea iba madurando en los círculos más inmediatos al trono y seguramente se hicieron nuevos contactos en las comarcas más decantadas a favor de la causa isabelina. Así las cosas, avanzado este mismo año, durante el difícil cerco de Burgos, el tema pudo haber brotado de nuevo -como recogen diferentes autores ${ }^{59}$ siguiendo el texto cronístico de Alonso de Palencia-, a través de una proposición de Juan de Ortega y Alonso de Quintanilla, aunque esta vez, por fuerza, con un mayor y más claro sesgo de carácter militar. Claro que de ninguna manera puede afirmarse que se trató así de fundar la Hermandad - cosa que, en todo caso, ya habría ocurrido meses antes - y hasta se ha dudado seriamente de la veracidad de esta noticia. En todo caso, lo que este relato pone en evidencia es que la idea de relanzar la institución, lejos de haberse relegado, permanecía muy viva y aún más, si cabe, dada la conveniencia de movilizar fuerzas para la guerra y unir a los favorables a la causa de la reina Isabel ${ }^{60}$. Sin embargo, los acontecimientos bélicos y los desordenes generados por los mismos, así como las deficiencias en las comunicaciones, hacían técnicamente inviable la posibilidad de dicho relanzamiento hasta que la situación político-militar hubiese llegado a una mínima estabilización.

Acabado el invierno de 1476 surgen propuestas ciudadanas encaminadas a formar agrupaciones capaces de atender a los grandes problemas de inseguridad que, sin duda, debieron agravarse a consecuencia del conflicto en curso. La más conocida es la decisión burgalesa del mes de marzo, consistente en poner en marcha un cuerpo armado, impulsado y sufragado por la ciudad y susceptible, en su caso, de enmarcarse a posteriori en una corporación más amplia que pudiera integrar los núcleos urbanos con la confirmación de la Corona ${ }^{61}$. Paralelamente, las villas de Tierra de Campos debieron llevar a efecto una iniciativa semejante, reu-

59 M. Lunenfeld, op. cit., p. 29; L. Serrano, op. cit., p. 170 ; L. Suárez fiernández, "La España...", cit., pp. 233-34.

so Y. Guefrero NAvarRete, "La Hermandad de 1476 y Burgos. Un factor decisivo en la transformación del poder municipal a fines de la Edad Media», AEM, 16, 1986, p. 536, se opone a la veracidad de esta propuesta de Ortega y Quintanilla durante el cerco del castillo de Burgos diciendo: "Nuestras fuentes no nos permiten constatar la veracidad de este hecho mencionado - personalmente nos inclinamos a no concederle demasiada veracidad-". Sin duda, aun aceptando este hecho como exponente de la perdurabilidad de la idea hermandina durante estos meses, lo que no es posible es darle ningún valor constituyente, de la misma manera que tampoco la ciudad de Burgos parece tener ningún papel en la construcción de la nueva entidad.

61 Esta iniciativa ha sido bien estudiada por $Y$. Guerrero Navarrete, op. cit., que reúne toda la documentación burgalesa sobre la cuestión. Entre dichos documentos recoge el acuerdo municipal para escribir a las ciudades del reino a fin de que se adhirieran a la propuesta, p. 549. 
niéndose para ello en San Cebrián de Mazote y redactando unos capítulos reguladores de la asociación que intentaban promover. En realidad, sabemos muy poco sobre estos hechos y lo único que podemos afirmar con seguridad es que un procurador presentó ante el concejo de Burgos los referidos capítulos ${ }^{62}$. De todos modos, lo que parece indudable es que ambas propuestas parecen ser exclusivamente concejiles - to es sin ninguna duda la burgalesa - y ajenas al poder real, de suerte que pueden asimilarse a viejas tradiciones hermandinas que por fuerza tenían que mantenerse vivas en las mentes de los dirigentes concejiles. En estas condiciones, lo que resalta de una manera más sobresaliente es que las dos iniciativas, tanto la burgalesa como la que impulsaban los reunidos en San Cebrián, contrastaban del modo más neto con la entidad plasmada en el ordenamiento de 1475, pues ésta era estrictamente monárquica y desarrollada por sus agentes.

De esta manera, durante los últimos días del invierno y primeros de la primavera de 1476 dos tendencias, basadas en el concepto hermandad, trataban de abrirse paso: la primera, inaugurada casi en los mismos comienzos del reinado y plasmada en unas ordenanzas dirigidas a todo el reino, era monárquica y buscaba asociar a todas las ciudades, pueblos y señoríos bajo la uniformidad del poder central; la otra, por el contrario, partía de los municipios y seguía los muchos ejemplos anteriores en los que la intervención regia se limitaba a confirmar el edificio político impulsado por los dirigentes locales. Las diferencias entre ambas formas de plantear la Hermandad son radicales y si se seguía - como así iba a ocurrir- el enfoque expuesto por los soberanos, la asociación de ciudades se convertiria decididamente en un instrumento al servicio del poder regio, por encima de las multiformes autoridades de ámbito local. Ahora bien, hay que dejar muy claro que ninguna de estas dos tendencias era nueva. Ambas pueden encontrarse en el reinado de Enrique IV y aún antes, pero es que además, ya entonces se vio que la hermandad impulsada por las ciudades realmente fracasó y terminó diluyéndose en 1469.

En esta etapa inicial del periodo de gobierno de los Reyes Católicos, las iniciativas ciudadanas que acabamos de recordar comienzan a configurarse con retraso respecto de las acciones de la corona. Además, en la medida en que la autoridad de los soberanos pudo afirmarse, los agentes del trono, mediante su unidad de acción, desbordaron las dispersas y localistas intervenciones urbanas. De este modo, cuando las ideas de los

62 L. Serrano, op.cit., p. 171; L. SuÁrez, op. cit., p. 240; Y. Guerrero, op. cit., p. 550, registra el acto de presentación de dichos capítulos en Burgos. 
burgaleses y de los hombres de Tierra de Campos, cada uno por su lado, comenzaron a convertirse en realidad, se estaba ya en las mismas vísperas de las Cortes de Madrigal y alli se iba a presentar un nuevo ordenamiento real sobre la Hermandad. Este ordenamiento es, como veremos, muy similar al anterior de 1475 y culmina una evolución que se había visto dificultada por las circunstancias de la guerra. En el contexto político existente en Castilla durante los primeros tiempos de los Reyes Católicos, las ciudades deseaban, como se ha dicho, la Hermandad, pero otra muy diferente a la que finalmente resultó.

En definitiva, no hubo convergencia entre las concepciones concejiles y reales ${ }^{63}$, como tampoco será posible aceptar de ningún modo que los monarcas se aprovecharon de la idea puesta en marcha por los burgaleses ${ }^{64}$, porque el planteamiento legal básico sobre el que se apoyará la institución procede del ordenamiento de 1475 , anterior a aquella. Por tanto, con toda propiedad podremos hablar de la Hermandad de los Reyes Católicos, y esa Hermandad era todo un síntoma de las posibilidades del autoritarismo monárquico sobre los poderes de ámbito local ${ }^{65}$.

Pero en realidad, la corporación que se perfila en la normativa de 1475 estaba muy lejos de lo que posteriormente será la Hermandad. Sus funciones eran mucho más limitadas y puede afirmarse que el proyecto se reducía a una asociación que aproximase las ciudades y tierras castellanas a la Corona, con el fin de garantizar la paz en los campos mediante la cooperación de las fuerzas locales. Es decir, se trataba de aprovechar desde el punto de vista de la Corte las posibilidades que en este sentido habían mostrado las recientes experiencias hermandinas y quizá por eso mismo la Hermandad no se veía como algo definitivo sino únicamente como un apoyo temporal. En realidad, el proceso de elaboración, tanto conceptual como práctico, de una Hermandad que sirviera, como lo hará después, a modo de instrumento de gran amplitud para el ejercicio del poder real, fue paulatino y encuentra aquí solamente un punto de partida.

63 Asi pues, nada más desacertado que afirmar: «concluyeron las Cortes de Madrigal con el regio espaldarazo a la solución tan tercamente perseguida por las grandes ciudades castellanas" J. Urosa Sánchez, Política, seguridad y orden público en la Castilla de los Reyes Católicos, Madrid, 1998, p. 159.

64 Como quiere A. Álvarez de Morales, op. cit., p. 142.

65 En el artículo ya citado de $\mathrm{Y}$. Guerrero se estudia certeramente la negativa reacción burgalesa ante la instauración de la Hermandad aprobada en las Cortes de Madrigal, no tanto por razones económicas, al menos en principio, sino por causas claramente politicas, y se concluye que la final aceptación de la nueva institución es exponente de la inferioridad de los poderes concejiles ante la legitimidad y predominio de la Corona. 
Así pues, el articulado de las ordenanzas de 1475 apenas se aleja de la herencia tradicional. La institución que se define carecía de todo soporte de ámbito global, más allá de la simple cooperación entre poblaciones bajo la dirección regia, y ni siquiera había la más mínima previsión en cuanto a la recaudación de recursos económicos. Faltan, por tanto, las características político-administrativas, militares o hacendísticas que posteriormente darán especial significación a la Hermandad como una etapa en el desarrollo de los medios para el ejercicio del poder monárquico.

Sin embargo, la Hermandad que se quiso poner en práctica en 1475 muestra una continuidad indiscutible con respecto a la impulsada por Enrique IV en 1473. Por lo que se refiere a la composición institucional, en ambos casos el eje está formado por los alcaldes y cuadrilleros ${ }^{66}$, si bien, los Reyes Católicos quisieron que la red fuese más tupida creando alcaldías en las aldeas de menos población que hasta entonces estaban desprovistas de ellas. Las juntas reciben una regulación más compleja en las ordenanzas de 1473 -donde podían ser generales, o bien, de ámbito regional, reuniendo a los núcleos de población dependientes de una ciudad, y también locales-, aunque en el texto más moderno tienen carácter regular y se descarta la iniciativa urbana que dos años antes se permitía. Destaca también la regulación más restrictiva que se hizo en 1475 de los casos de hermandad, ciñéndose con mayor precisión a los delincuentes que actuaban en despoblado y, por supuesto, se acude al apellido como medio de persecución y al asaeteamiento como pena de muerte.

En definitiva, los Reyes Católicos recogieron en su primer ordenamiento de Hermandad la herencia de la corporación inmediatamente precedente de una manera absolutamente directa, añadiendo mayor precisión a los preceptos legales y -no podía ser de otro modo- una indiscutible propensión a la centralización.

Después, las ordenanzas de Madrigal, que se promulgaron en 1476, son en su mayoría una copia literal de las anteriormente emitidas en Segovia ${ }^{67}$. Hay una variación notable en el comienzo, al sustituir la orden directa de formación de la Hermandad por un nuevo tenor en el que se menciona la petición de los procuradores a Cortes y se añade: «...e para

66 El binomio alcaldes-cuadrilleros será respetado en los posteriores ordenamientos y al final, después de 1498, será lo único que quede de la institución, una vez disueltos sus restantes organismos. En este orden de cosas, hay que hacer notar que la herencia de la añeja Hermandad Vieja de Toledo, Talavera y Ciudad Real quedó reducida a los aspectos técnicos y jurídicos más relacionados con la seguridad.

67 No puede extrañar que A. Álvarez de Morales, op. cit., p. 146, observara su similitud con las de Villacastín de 1473. 
ello deputamos algunas personas del nuestro Consejo que entendiesen con los dichos procuradores en uer e ordenar la manera que se deuiese tener...", lo que, como sabemos, de ninguna manera abre la puerta a la iniciativa ciudadana sino que se refiere a la presentación del nuevo ordenamiento ante los reunidos en Madrigal y, por lo demás, las restantes diferencias entre los dos textos son muy limitadas: se amplían ligeramente los plazos para la formación de la Hermandad, también la consideración del despoblado — desde el lugar menor de quince vecinos al inferior a cincuenta que no tuviese cerca- $y$, asimismo, se introducen algunas modificaciones en la exposición de los casos de hermandad que, sin suponer innovaciones sustanciales, añaden específicamente la expresión "salteamiento de caminos" y concretan mejor la necesidad de que los delitos aconteciesen en despoblado. No obstante, se insertan dos nuevos preceptos que no habían encontrado lugar en el texto de 1475 y que aunque de trascendencia desigual debemos referir. Por el primero, se ordenaba que los viajeros fuesen abastecidos por sus dineros sin cobrarles precios abusivos, idea que ya aparecía en 1473, y por el segundo - y esto es muy importante - se creaba el arca de la Hermandad que obligatoriamente debía tener cada concejo para la financiación de los gastos de la entidad, cuyos recursos podían obtenerse: “...por sisa o por repartimiento o tomarlos de los propios del conçeio o en otra manera qualquier que cada conçeio viere que los podrá sacar mejor e mas syn dapno del pueblo...". Este aspecto no había sido incluido antes, pero es, sin ninguna duda, absolutamente fundamental, porque a partir de este escueto mandato se constituirá una compleja maquinaria fiscal capaz de sostener los organismos y fuerzas hermandinas.

De este breve análisis comparativo de los ordenamientos aprobados en 1475 y 1476 resulta claramente una absoluta continuidad, mediante la cual se puede constatar que las ideas expuestas por los soberanos al poco de acceder al trono encuentran su verdadera vigencia un año después. Por esto mismo, la institución que se perfila en 1476 todavía permanece fuertemente anclada en el pasado en lo que se refiere a sus aspectos orgánicos, aunque era un principio más que suficiente para un desarrollo posterior que se llevaría a efecto muy pronto a lo largo de las juntas celebradas aquel mismo verano. Por consiguiente, en el transcurso de las mismas se fue produciendo el verdadero proceso de dotación institucional de la corporación.

Efectivamente, de las Cortes de Madrigal salió sólo la consagración de un concepto: la Hermandad encarrilada y dirigida por la Corona, pero quedaban por resolver la mayor parte de los problemas, tanto los referentes a la organización de la entidad como todos los que planteaba su desarrollo 
práctico y su misma aceptación en los diferentes ámbitos geográficos de todo el reino. Por eso, los soberanos, una vez que las sesiones de las Cortes hubieron acabado, tuvieron que enviar a sus delegados para que visitasen diferentes ciudades y entablasen contactos con los representantes de los concejos ${ }^{68}$, se celebraron reuniones - Becerril de Campos, Valladolid-y se inició un proceso que cabe muy bien definir como constituyente. Fruto del mismo será la Hermandad General, uniformemente organizada a partir de un fuerte control central y suficientemente dotada para el desenvolvimiento de las finalidades militares, administrativas, hacendísticas o de seguridad que propiamente harán de ella un instrumento para el ejercicio del poder regio. Dicho proceso se desarrollará al paso de las juntas generales que se celebraron sucesivamente en Cigales, Dueñas, Santa María de Nieva, segunda de Dueñas, Burgos y Pinto-Madrid ${ }^{69}$, y a partir del verano de 1476 y hasta la definitiva cristalización del edificio institucional hermandino, la constitución de la entidad sigue dos líneas paralelas absolutamente imprescindibles para que pudiera consolidarse: una de ellas dedicada a la formulación y puesta en práctica de un esquema orgánico adecuado al funcionamiento netamente centralizado que se deseaba y otra encaminada a la difícil aceptación de la corporación en todas las tierras del reino.

A la vista de lo que llevamos expuesto, cabe distinguir dos fases a la hora de resumir los pasos iniciales de la nueva institución. La primera de dichas fases consiste en una etapa de preparación que se basa en las ideas reflejadas legislativamente en el ordenamiento de 1475 y que culmina en abril del año siguiente, cuando los procuradores escucharon en las Cortes el articulado del texto legal que la Corona les presentó. La segunda supone la conversión de aquella Hermandad, que todavía se atenía a la tradición en casi todo lo refe-

68 Pulgar nos dice que Ortega y Quintanilla «fablaron con algunos homes principales de las çibdades e villas de Burgos e Palencia, e Medina, e Olmedo, e Avila, e Segovia, e Salamanca, e Zamora, e de aquellas partes, mostrándoles los males e daños que padecían e quanto mayores los esperaban si con tiempo no se remediasen. Estos, cada uno en sus pueblos, platicaron esta materia e al fin ovieron su acuerdo, que cada çibdad e villa enviase sus procuradores, los quales se juntasen a dia cierto en la villa de Dueñas...". Crónica de los señores Reyes Católicos don Fernando e doña Isabel de Castilla y de Aragón, en Crónicas de los reyes de Castilla, Madrid, 1953, III, p. 300.

69 Conviene recordar en este punto que las muchas necesidades de organización de la naciente entidad hicieron que estas primeras juntas se celebrasen a un ritmo muy rápido, de forma que tres hubo en 1476 y dos en 1477. Se publican todos estos ordenamientos y se presenta la problemática de esta etapa formativa de la Hermandad en Y. Guerrero NavarRete y J. M. SÁNCHEZ BENITO, "El proceso constituyente de la Hermandad General. Los ordenamientos de 1476 a 1478", AHDE, 1989. 
rente a su organización, en un mecanismo político mucho más desarrollado y lleno de innovaciones al servicio de la acción monárquica.

Pero esta segunda etapa no resultó nada fácil y un solo dato nos servirá para mostrarlo. Las primeras juntas generales tuvieron una asistencia muy limitada, restringida únicamente a los núcleos del valle del Duero. Dicha asistencia tan sólo fue ampliándose lentamente en la medida en que, con innumerables dificultades, progresaba la afirmación de la Hermandad en las diferentes regiones del reino. Así que hay que esperar a la reunión celebrada sucesivamente en Pinto y Madrid en 1478 para que se pudiera hablar con propiedad de «junta general de diputados, e procuradores, e mensajeros de las çibdades, e villas e lugares, seysmos e merindades destos reynos de Castilla e de León, de Toledo e del Andaluzía».

Sin duda, eran varios los factores que en cada lugar podían conjugarse de manera diversa, según los casos, en la oposición al afianzamiento del proyecto hermandino: desde las circunstancias de la guerra al temor a nuevas cargas fiscales, pasando sobre todo por las reservas de los poderes locales -nobles y concejos-que se resistían a perder peso en el entramado de equilibrios que componía el juego político del reino castellano. Por eso la integración en el seno de la Hermandad de los diversos ámbitos fue difícil y siguió un paso muy desigual, según la capacidad de maniobra y negociación de cada uno de ellos.

En el caso de Cuenca el proceso de organización de la nueva entidad se desarrolló con la mayor facilidad. El día cinco de mayo de 1476 el procurador síndico de la ciudad presentaba ante el concejo las ordenanzas recién aprobadas en Madrigal y sólo ocho días más tarde no solamente se aceptó su cumplimiento sino que, a la vez, se designaron alcaldes y cuadrilleros que juraron sus cargos en la jornada siguiente ${ }^{70}$. Así es que la iniciativa se había aceptado de manera inmediata y efectiva al arbitrar los medios para el funcionamiento de la entidad desde un primer momento. Pero naturalmente si esta conducta puede comprenderse con facilidad atendiendo a la actitud sumisa de los dirigentes de la ciudad, claramente plegados a la política regia, contrasta no poco con otros muchos casos, cual por ejemplo Toledo o Burgos ${ }^{71}$.

Así las cosas, la articulación de la Hermandad en el ámbito conquense siguió su curso con rapidez. Todavía en el mes de mayo se iniciaron conversaciones con otras localidades dependientes de jurisdicciones ajenas a

70 A.M.Cu. Leg. 200, exp. 1, fols. $17 v-21 r$ y $21 v-23 r$.

71 Ver sobre el caso burgalés el artículo varias veces referido de Y. Guerrero Navarrete. 
la ciudad, de cara a la configuración de la correspondiente provincia hermandina, y curiosamente se inician con la villa de Castillo de Garcimuñoz, perteneciente al marquesado de Villena, cuyo titular estaba firmemente enfrentado a los Reyes Católicos y, por tanto, a la ciudad de Cuenca. Claro que, en realidad, no se trataba de hablar únicamente sobre el comienzo de la Hermandad, porque el objetivo más evidente de la negociación con esta villa consistía en alcanzar algún acuerdo sobre los choques armados que tenían lugar entre ambos núcleos de población, y por eso no es extraño que en el resultado final de las conversaciones ni siquiera se mencionen los temas referidos a la naciente corporación ${ }^{72}$. No podía esperarse otra cosa en un clima de hostilidades abiertas. Sin embargo, en otras zonas en las que no había problemas comparables, se logró inmediato acuerdo para el ingreso en la Hermandad ${ }^{73}$.

No hubo pues resquemor ni menos aún resistencia a los mandatos reales, sólo obediencia y disponibilidad por parte del concejo conquense, pero precisamente por causa de esa actitud un problema de gran importancia iba a seguir desestabilizando el devenir político de esta región, dificultando asimismo la completa configuración territorial de aquella provincia hermandina. Me refiero al enfrentamiento contra el marqués de Villena, cuyo señorío se extendía al sur de la tierra de Cuenca ${ }^{74}$, y cuya actitud en la guerra civil es bien conocida ${ }^{75}$.

Pero si la integración de Cuenca en las estructuras de la Hermandad lo que muestra es docilidad ante la voluntad regia, sabemos muy bien que en muchos rincones del reino las cosas discurrieron de forma muy distinta, y en este sentido la ciudad de Toledo nos puede servir como punto de comparación con respecto al caso conquense.

Inicialmente, la urbe toledana, una de las más importantes de Castilla, no mostró el menor interés por formar parte de la nueva organización. Hace ya bastantes años Benito Ruano hizo referencia a esta cuestión y, siguiendo de cerca la información cronistica, puso de relieve las dificultades que se encontraron, especialmente, por parte de los grandes ${ }^{76}$.

A.M.Cu. leg. 200, exp. 1, fols. 30r-31r.

A.M.Cu. leg. 200 , exp. 1 , fols. $46 \mathrm{v}$ y $47 \mathrm{v}$.

Ver sobre el papel de Cuenca en este conflicto mi artículo "La sociedad urbana ante la guerra a fines de la Edad Media. El caso de Cuenca en los conflictos militares de los Reyes Católicos", Revista de Historia Militar, 71, 1991. Por otra parte, la documentación pone de relieve con toda claridad la intervención de la Hermandad en estas luchas: A.M.Cu. leg. 201, exp. 1, fols. $7 r-v$ y $103 v$; leg. 201, exp. 2, fols. 2v-5r.

75 Ver J. TORRES FONTES, "La conquista del marquesado de Villena en el reinado de los Reyes Católicos", Hispania, 50, 1953, pp. 37-151.

76 E. Benito Ruano, Toledo en el siglo xv, Madrid, 1961, pp. 123-24. 
Pero también es verdad que inmediatamente después de Madrigal los soberanos concentraron su atención en la submeseta septentrional -que constituía el eje tradicional y todavía durante mucho tiempo fundamental de los estados de Castilla-, de forma que aquellos núcleos urbanos son los únicos que aparecen claramente mencionados en la documentación hermandina de 1476.

No obstante, en dicho año se habían iniciado negociaciones entre la Corona y los toledanos sobre este asunto. Tales negociaciones debieron ser difíciles y, desde luego, discurrieron con gran lentitud, así que, al igual que se hizo en otros lugares, los soberanos mandaron un comisionado -en este caso Bartolomé Malaver de Zafra- para que se encargase de dar forma a la Hermandad. De esta suerte, al llegar el siguiente año, 1477, Toledo había ingresado en ella, aunque su presencia en el seno de la misma seguía mostrando innumerables dificultades y casi todo estaba por hacer. En este contexto, Malaver de Zafra recibió poderes para ocuparse "de las cuentas de lo pasado" - un tema espinoso del que hubo de encargarse el corregidor Gómez Manrique-, mientras que la propia Corona tuvo que intervenir directamente en la provisión del cargo de diputado, con lo cual se suscitaron nuevas diferencias que todavía se mantenían en la primavera y que, finalmente, obligaron a los monarcas a ceder en este punto. Claro que consiguieron, eso sí, que se pusieran en marcha los oficios de la institución y los resortes administrativos y hacendísticos de la misma ${ }^{77}$.

Así pues, sólo entonces - primavera de 1477- pudo culminar la organización hermandina en la ciudad de Toledo ${ }^{78}$, aunque seguía pendiente el efectivo ingreso de las villas y pueblos que se situaban en su ámbito de influencia. Por consiguiente, los soberanos se dirigieron a todas estas poblaciones para que en relación con la urbe procediesen a agruparse en hermandad y a adecuar los diferentes elementos institucionales que los ordenamientos contemplaban ${ }^{79}$. De esta manera debió comenzar a formarse

77 A.M.To. Archivo Secreto, caj 2, leg. 1, n. 4.

78 El 16 de abril de 1477 los reyes escribían al corregidor de Toledo para que se pagase del arca de la Hermandad a Bartolomé Malaver de Zafra, entendiendo que su tarea organizadora había llegado a buena conclusión. A.M.To. Arch. Secreto, caj. 2, leg. 1, n. 6. Hubo en el reino otros casos no menos dificiles que no podemos entrar a analizar aqui. Por ejemplo, Sevilla, a cuyo concejo llegaron misivas reales entre diciembre de 1476 y enero de 1477 , pero donde tan sólo a fines de este año puede considerarse que estaban puestas las bases de la institución. Algunas noticias al respecto en C. López Martinez, La Santa Hermandad de los Reyes Católicos, Sevilla, 1921 , pp. $67-73$. Adernás, muchas veces las ciudades respondieron con pasividad a los requerimientos de la Hermandad.

79 A.M.To. Arch. Secreto, caj. 2, leg. 1, n. 5, A.G.S. R.G.S. 1477-IV tol. 118 y B.N. mss. 13030 , fols. $88 \mathrm{r}-90 \mathrm{~V}$, carta mencionada por A. PAZ Y MELIA, «La Santa Real Hermandad Vieja y la Nueva Hermandad General del Reino", RABM, 3, 1897, p. 107, que de un modo excesivamente 
la provincia con mucha lentitud. Esto es así a tal punto que en el verano hubo que escribir, en tono verdaderamente duro, a los concejos que no participaban en la financiación de la entidad y tampoco mandaban sus representantes como debían. Se llegó a amenazarles con poner en práctica las penas que los ordenamientos preveían para los que no querían integrarse en la Hermandad - «...non trataren con los que ansy non queredes entrar, ni ser, ni vos juntar con ellos en la dicha hermandad e vos costriñeren e apremiaren...»-y, desde luego, la provincia como tal apenas si había dejado de ser un mero deseo expresado sobre el papel ${ }^{80}$. Sin embargo, a lo largo de este año la nobleza de la región, ante las presiones de los reyes, iba aceptando poco a poco la Hermandad ${ }^{81}$ y al reunirse en 1478 la junta general de Pinto y Madrid, la provincia toledana debia ser ya una realidad efectiva ${ }^{82}$.

\section{APÉNDICE DOCUMENTAL}

1475, febrero, 20. Segovia

A. M. de Cuenca leg. 16, exp. 4 (original) y leg. 1145, exp. 2 (copia).

Ordenamiento de la Hermandad General ${ }^{83}$.

Don Fernando e doña Isabel, por la graçia de Dios rey e reyna de Castilla, de León, de Toledo, de Ceçilia, de Gallizia, de Seuilla, de Cordoua, de Murçia, de Jahen,

optimista creía que había permitido la consolidación de la Hermandad al sur de los puertos del Sistema Central.

80 B.N. mss. 13119 , fols. $111 \mathrm{r}-12 \mathrm{v}$.

81 Durante la primavera de 1477 los reyes presionaron a los nobles que estaban en la Corte y se dirigieron por escrito a los que residian en la ciudad y comarcas toledanas. A.M.To. Arch. Secreto, caj. 1, leg. 1, n. 15, documento publicado por E. Benito Ruano, op. cit., n. 89. Desde luego, el problema en Toledo no era la incompatibilidad de la nueva institución con la Santa Hermandad Vieja de Toledo, como se dijo hace años y todavía repetía más recientemente $E$. Martinez RuIz, "Algunas reflexiones sobre la Santa Hermandad", Cuadernos de Historia Moderna, 13,1992, p. 100. Por supuesto, tampoco puede aceptarse que "el reconocimiento de la Santa Hermandad Vieja ... había determinado la paralela conversión de Toledo, Talavera y Ciudad Real en cabeceras provinciales", como dice J. Urosa Sánchez, op. cit., p. 188, confundiendo del todo el papel de la Hermandad Vieja, que de ninguna manera debe mezclarse, como hace insistentemente este autor, con la nueva que los Reyes Católicos impulsaban. Sabido es que nada tienen que ver ambas entidades ni en sus fines, ni en su organización, ni en su trayectoria histórica.

82 El ámbito geográfico inicialmente previsto para la provincia toledana sufrió modificaciones al constituirse separadamente, como demarcación especifica, el territorio del arzobispo de Toledo.

83 Este texto se publicó hace unos años en mi trabajo "Consideraciones sobre los orígenes de la Hermandad de los Reyes Católicos. Un ordenamiento inédito de 1475 ", incluido en Castilla, los Reyes Católicos y..., cit., pp. 28-35. La mínima difusión que tuvo este librito y el interés del ordenamiento nos lleva a editario ahora. 
del Algarbe, de Algesira, de Gibraltar, príncipes de Aragón, e señores de Vizcaya e de Molina. A los duques, marqueses, prelados, ricosomes, e maestres de las hordenes, priores, e a los del nuestro Consejo e oydores de la nuestra Audiençia, alcalldes, e notarios, e otras justicias, e ofiçiales qualesquier de la nuestra Casa e Corte e Chancillería, a los comendadores e subcomendadores, alcaydes e tenedores de los castillos e casas fuertes, a todos los conçejos, corregidores e asistentes, alcalldes, alguasiles, merinos, regidores, caualleros, escuderos, ofiçiales e omes buenos de todas las çibdades e villas e logares de los nuestros regnos e señoríos, e a otros qualesquier súbditos naturales de qualquier ley, e estado e condición, preeminençia e dignidad que sean, e a cada vno o qualquier de vos a quien esta nuestra carta fuere mostrada o su traslado signado de escribano público; salud e graçia. Bien sabedes e a todos es notorio quantas muertes, e feridas de omes, e prisiones dellos, e robos, e tomas de bienes e salteamientos, e otros delitos e maleficios son fechos e cometidos de dies años a esta parte en los caminos, e yermos e despoblados, por muchas presonas, robadores e salteadores de caminos, e como muchos dellos por las discordias e mouimientos que auían en estos dichos nuestros regnos quedaron sin reçebir pena e castigo por los tales delitos e maleficios, porque se presumen que algunos destos continuando su mal beuir tentarán de aquí delante de cometer e faser los tales e semejantes delitos, a lo qual nos, deseando faser e conplir con aquello a que somos obligados, entendemos, con la ayuda de nuestro Señor, obuiar, dando orden en la execuçión de nuestra justicia como los tales maleficios çesen y los perpetradores dellos sean punidos, e los buenos biuan en pas e sosiego, e a cada vno sea guardada su justicia; y para entre tanto que en esto damos orden y la ponemos en execuçión es nuestra merçed e voluntad que sean fechas hermandades por vosotros en todas las çibdades e villas e logares de los dichos nuestros regnos e señoríos, asy realengos como de señoríos, e de hórdenes e de behetrías, cada çibdad e villa por sy con su tierra e término e juridiçión para con ellos mismos, e eso mismo para con las otras tierras e partidos de sus comarcas, e para se responder e ayudar las vnas a las otras por vía de hermandad, solamente para en los casos de yuso contenidos e non para mas ni allende, las quales dichas hermandades mandamos e hordenamos que sean regidas $e$ gouernadas por las hordenanças siguientes.

Primeramente, mandamos e hordenamos que todas las dichas prouinçias, merindades, e valles, e çibdades, e villas e logares de los dichos nuestros regnos, cada çibdad e villa por sy e por su tierra e término, fagan la dicha hermandad vnas con otras e otras con otras, e todas juntas vnas con otras dentro de veynte dias después que fuere noteficada e pregonada esta nuestra carta o el dicho su traslado signado, e que la vengan a faser e jurar cada pueblo a la cabeça del arçobispado e obispado, arçedianadgo o merindad de donde fuere, e quel tal conçejo que asy fuere cabeça de su partido sea tenido dentro de los dichos veynte días de notificar esta dicha carta y la faser publicar e pregonar por todas las çibdades, e villas e logares que entran en su partido, por manera que dentro de los dichos veynte dias ayan fecho, e firmado e jurado la dicha hermandad las çibdades, e villas, e logares, e prouinçias e merindades de cada vn partido entre sy mismos para con todas las otras prouinçias, e valles, e merindades, çibdades, e villas e logares de los dichos nuestros regnos, e lo notifiquen asy dentro de otros dies días siguientes a las çibdades e villas e logares comarcanos a ellos que son cabeça de otros arçobispados, e obispados, o merindades o otros partidos, e sy e sy (sic) no lo fisieren e cumplieren en todo e por todo que cayan e incurran en pena de veynte mill mrs., la meytad para nuestra Cámara e la otra meytad para las costas de la dicha hermandad. 
Otrosy, ordenamos e mandamos que la dicha hermandad sea fecha entre vosotros solamente para en los casos siguientes: muertes, e feridas de omes, e prisiones dellos, e fuerças, e robos, e tomas de bienes, e salteamientos o qualquier cosa dello que fuere fecho e cometido en camino, o en yermo e despoblado, e declaramos que qualquier cosa de las susodichas fecha e cometida en logar de quinse vecinos o dende ayuso se entienda ser fecha e cometida en yermo e despoblado. E otrosy, que sea caso de hermandad quema de hedefiçios, e de mieses, e viñas quier sea fecha la quema en despoblado o en poblado. E otrosy, que sea caso de hermandad si qualquier onbre que ouiere muerto a otro de muerte segura en poblado o en yermo fuyere e saliere a 10 despoblado fuyendo, e sy quebrantare casa, e robare en ella, e fuere al yermo e despoblado, e si estando alguno preso en carçel por crimen quebrantare la carçel e fuyere della, e se fuere fuera a lo yermo e despoblado, e que non pueda conoçer la dicha Hermandad sobre otro ni otros casos saluo sobre estos e sobre el caso siguiente.

Otrosy, bien sabedes quantas presiones de omes, robos e tomas de bienes se an fecho de los dichos dies años a esta parte e se fasen de cada día en estos nuestros regnos so color e por nonbre de prendas e represarias, por virtud de algunos preuillejos o cartas que del señor rey don Enrique, nuestro hermano, cuya ánima Dios aya, fueron dadas e libradas, o de los sus contadores mayores, en que fueron puestos por executores en algunas dellas las presonas que eran partes, e en otras algunas presonas non conocidas o de mal beuir, so color de faser prendas refrecuentan el robar, de lo qual se ha seguido grand dapno a nuestros súbditos e naturales porque muchos dellos han pagado lo que no deue e otros algunos han pagado lo que otros deuen. Por ende, por euitar grandes inconbinientes, nos, de nuestra çierta ciencia e propio motu, reuocamos qualesquier executores que fasta aquí fueron dados por el dicho señor rey nuestro hermano por qualesquier preuillejos, e çédulas, e alualaes, cartas quier sean firmadas de su nombre e sobre escriptas de los sus contadores mayores, o quier sean dadas e libradas por los dichos sus contadores mayores, saluo en quanto por ellos es cometida la execuçión de las tales prouisiones a las justiçias ordinarias, e mandamos que de aquí adelante otras presonas algunas non executen las dichas sus cartas e preuillejos ni otras prouisiones suyas algunas por vía de execuçión ni de prendas ni represarias avnque en las tales prouisiones estén especialmente nombradas, saluo las dichas justiçias ordinarias a quien dirigen por via de execuçión, e sy otros algunos se entremetieren a faser execuçión o prendas o represarias por virtud de las dichas cartas de preuillejose otras prouisiones que este tal sea caso de hermandad de más e allende de los otros casos de suso expresados, e sy contra la parte que pidiere la tal execuçión o a cuyo pedimiento se fisieren las prendas e represarias como contra el executor que las fisiere e contra los que con él fueren, los quales todos sean auidos por robadores notorios e ayan aquella misma pena que por caso de hermandad deue ser dada a los robadores.

Otrosy, hordenamos e mandamos que para proseguir los delinquentes e malfechores oestos dichos casos o qualquier dellos estedes ordenados e vos juntedes a bos de hermandad en esta guisa. Que en cada çibdad e villa e logar luego sean deputados alcalldes, conbiene a saber, sy el logar fuere de treynta vecinos o dende ayuso vn alcallde, e sy fuere de treynta vezinos arriba dos alcalldes puestos por el conçejo e ofiçiales del tal logar. Otrosy, sean nombrados e puestos quadrilleros considerada la grandeza e dispusiçión de cada vna çibdad o villa o logar a bien vista de su conçejo, y que estos a tales luego quel tal delito les fuere denunciado, si paresçiere parte que lo denunçie, o sy non paresçiere luego que lo supieren de su oficio sean tenidos de mandar y faser seguir a los malfechores fasta çinco leguas dende, faziendo 
dar todavía apellido e repicando las campanas en cada logar a donde llegare para que eso mismo salgan en seguimiento de los malfechores, e quando e cada vno legare en cabo de las çinco leguas de donde cada vno salió que dexare rastro a los otros, e así de logar en logar e de tierra en tierra prosigan los malfechores fasta los prender o los çercar e echar fuera del reyno, e los malfechores que asy fueren presos que sean traídos al logar e término a donde delinquieron, e sy allí touieren juridiçión allí se execute la justicia, e sy no la touieren dentro de tres días después que llegaren ende con el malfechor sean tenidos de lo notificar e notificaren a los alcalldes de la Hermandad de la çibdad o villa o logar a cuya juridiçión fueren sujebtos para que vengan luego al tal logar donde estouiere preso el malfechor e allí conozca de la cabsa e execute la justicia en vno con el alcallde o alcalldes de la hermandad de aquel logar, pero quel alcallde o alcalldes de la hermandad del logar en cuyo término se cometió el delito puedan entre tanto reçebir la querella e la información y faser otros abtos que se ouieren de faser fasta la sentençia definitiua sy quisieren que non puedan sentenciar ni executar sin los dichos sus mayores, e si dentro de los dichos tres días non vinieren los dichos mayores, como dicho es, quel alcallde o alcalldes de la hermandad del tal logar puedan faser condenación e execuçión por el delito syn más esperar a los dichos alcalldes de la juridiçión a donde son sujeblos, e esto se entienda sy el tal logar donde estouiere preso el malfechor estouiere çinco leguas o más çerca de la çibdad o villa o logar a cuya juridiçión es sujebto, pero sy estouiere allende de çinco leguas que sea en eleçión del conçejo del tal logar donde estouiere preso el malfechor o que sea judgado e sentenciado el malfechor por los alcalldes de la hermandad de aquel logar juntamente con los alcalldes de la hermandad del logar más cercano delios que fuere de çient vesinos o dende arriba, o de recorrer a la çibdad o villa o logar a cuya juridiçión son sujebtos para que se determine la cabsa, como arriba en este capítulo se contiene, bien como si estouiesen dentro de las dichas çinco leguas, pero si fuere el logar de juridiçión sobre sy que puedan vsar libremente della en los casos e por caso de hermandad. E qualquier que quebrantare lo contenido en esta hordenança o qualquier cosa o parte dello que caya e incurra por cada ves en pena de dos mill mrs. para las costas de la dicha hermandad.

Otrosy, mandamos a vos los dichos conçejos, ofiçiales e omes buenos de qualesquier çibdades, e villas e logares de los dichos nuestros regnos, así de realengo como de señorío, e hórdenes e behetrías, e a los dichos alcaydes e tenedores de qualesquier castillos e fortalesas fuertes a donde se ençerraren qualesquier malfechores, e a los prelados e caualleros cuyos fueren que luego que qualesquier alcalldes, o quadrilleros o otras personas a bos de la dicha hermandad vinieren en prosecución del tal malfechor que luego gelo entreguedes libremente en su poder, e sy dixierdes que no está ende o non sabedes donde está dexedes e consintades en las çibdades e villas e logares a todos los que asy fueren en seguimiento de los malfechores buscar e escodriñar, e por quantas vías quisieren e mejor pudieren, los tales malfechores, e vos los dichos alcaydes e tenedores dexedes e consintades entrar en esos dichos castillos e fortalezas e cada vno dellos a tres o quatro omes dellos syn armas, e buscar e ynquerir ende los tales malfechores, e fallados gelos entreguedes libremente, so pena de la nuestra merçed e de diesmill mrs. para la dicha hermandad, e que cayan e incurran en la misma pena que deuia auer el malfechor si les fuere entregado, la qual pena sea dada por caso de hermandad e por los alcalldes della, e demás que paguen al querelloso todos los dapnos e costas que sobre ello ouiere fecho.

Otrosy, mandamos que desde el dya que esta nuestra carta o el dicho su traslado signado viniere a vuestra noticia en qualquier manera, fasta çinco dyas primeros si- 
guientes, qualquier çibdad o villa o logar que tiene juridiçión sobre sy eliga e ponga luego los dichos alcalldes de hermandad como dicho es, e el vno sea del estado de los caualleros e escuderos, e el otro del estado de los çibdadanos e pecheros, tales que sean idóneos e pertenesçientes para ello, los quales vsen los dichos oficios por seys meses e non más, e asy dende en adelante los pongan e nombren de seys en seys meses, e non aya ni le sea dado salario alguno saluo sus derechos de los actos que fisiere segunt que los lieuan los alcalldes del pueblo. E sy por ventura en algunas de las dichas çibdades e villas e logares non vos pudierdes acordar en la elección e nombramiento de los tales alcalldes, por la presente mandamos al conçejo e ofiçiales donde esto acaesçiere, so pena de la nuestra merçed e de priuaçión de los oficios, que dentro de otros dies dias nos lo enbiedes noteficar porque nos nombremos los tales alcalldes.

Otrosy, mandamos que todos los quadrilleros e otras presonas de cada pueblo sean tenidos de obedesçer e obedescan el mandamiento de su alcallde o alcalldes de la hermandad en lo que a ella toca e atañe so las penas que por los dichos sus alcallde $o$ alcalldes de hermandad sobre ello les fuere puesto, las quales ellos mesmos puedan esecutar e executen en las presonas e bienes de los desobidientes por las penas en que incurrieren las presonas e conçejos trasgresores destas nuestras hordenanças que las puedan esecutar e executen los alcalldes de la hermandad de la çibdad o villa o logar que sobre tal conçejo o persona delinquente ternía juridiçión hordinaria, pero si los tales alcalldes no fueren poderosos o fueren nigligentes para esecutar que en el tal caso la junta de la hermandad de aquel partido executen las tales penas.

Otrosy, hordenamos e mandamos que los alcalldes de la dicha hermandad, reçebida la querella e procediendo de su ofiçio, como dicho es, podiendo aver el malfechor lo prendan, e sabida la verdad, sinpliçer e de plano sin estrépito e figura de juiçio, lo condepnen por su sentencia, e la executen segund el tenor de las nuestras hordenanças si pudiere ser auido, e si non pudier ser avido que los alcalldes de la hermandad e qualquier dellos a quien perteneciere el conoçimiento faga, segund la horden de suso dada, proçeso contra el tal malfechor, pregonándolo por tres pregones en nueue días, dando de tres en tres días vn pregón, e al postrero día de los nueue días ayan el pleito por concluso e dende en adelante, avida primeramente la información, en rebeldía del delincuente, lo puedan condepnar e condepnen a la pena que meresçiere segund curso desa hermandad, bien asy como sy en persona fuese çitado sobre ello, pero es nuestra merçed que sy el tal condepnado después de fecha la condenaçión se ofreciere e presentare de su voluntad a la carçel de la Hermandad que sea oydo e le sea guardada su justicia purgando e pagando primeramente las costas, non enbargante la dicha condenaçión, para lo qual todo faser e complir e executar damos poder conplido a los alcalldes de hermandad e a cada vno dellos que asy por vos e cada vno de vos fueren nombrados e puestos en la forma susodicha.

Otrosy, hordenamos e mandamos que qualquier persona que fuere condepnada a pena de muerte por caso de hermandad, por qualquier de los casos della, que la muerte le sea dada públicamente, e sea muerto con saetas en el canpo segund se acostumbra faser en tiempo de las otras hermandades pasadas.

Otrosy, hordenamos e mandamos que cada çibdad, o villa, o prouinçia, e valle, e merindad, o partido se junten en cada vn año vna ves en la cabeça de tal partido a bos de hermandad para esecutar las penas e para entender e proueer en todas las cosas que vieren ser conplideras al buen estado de la dicha hermandad, no la estendiendo más ni allende de lo contenido en esta nuestra carta, porque vos mandamos 
que veades las dichas hordenanças de suso encorporadas, e las guardedes e cumplades, e fagades guardar e complir en todo e por todo segunt que en ellas e en cada vna dellas se contiene, y contra el tenor e forma dellas ni de alguna dellas non vayades ni pasedes, ni consyntades yr ni pasar en algunt tiempo ni por alguna manera en quanto nuestra merçed e voluntad fuere, para lo qual todo faser e executar segunt que de suso se contiene vos damos poder conplido, e sy para la execuçión dello menester ouierdes fauor e ayuda los vnos de los otros mandamos vos que vos dedes vnos a otros todo el fauor e ayuda que menester fuere, e que vos las dichas justiçias, cada vno de vos en vuestros logares e juridiçiones, fagades luego pregonar públicamente o el dicho su traslado signado, e los vnos ni los otros non fagades ni fagan ende al por alguna manera so pena de la nuestra merçed e de las penas de suso contenidas so las quales mandamos a qualquier escriuano público que para esto fuere llamado que de ende al que esta nuestra carta vos mostrare o el dicho su traslado signado como dicho es testimonio signado con su signo porque nos sepamos en como se cumple nuestro mandado. Dada en la muy noble çibdat de Segouia, veynte dyas de febrero, año del nasçimiento del nuestro Señor lhesuchristo de mill e quatroçientos e setenta e çinco años. Yo el rey (rubricado), Yo la reyna (rubricado). Yo Alfonso de Auyla, secretario del rey e de la reyna nuestros señores, la fis escriuir por su mandado. 